University of Wollongong

Research Online

Faculty of Engineering and Information

Faculty of Engineering and Information

Sciences - Papers: Part A

Sciences

$1-1-2016$

State of the art of control schemes for smart systems featuring magnetorheological materials

\author{
Seung-Bok Choi \\ Inha University \\ Weihua Li \\ University of Wollongong, weihuali@uow.edu.au \\ Miao Yu \\ Chongqing University \\ Haiping Du \\ University of Wollongong, hdu@uow.edu.au \\ Jie Fu \\ Chongqing University
}

See next page for additional authors

Follow this and additional works at: https://ro.uow.edu.au/eispapers

Part of the Engineering Commons, and the Science and Technology Studies Commons

Research Online is the open access institutional repository for the University of Wollongong. For further information contact the UOW Library: research-pubs@uow.edu.au 


\title{
State of the art of control schemes for smart systems featuring magneto- rheological materials
}

\begin{abstract}
This review presents various control strategies for application systems utilizing smart magnetorheological fluid (MRF) and magneto-rheological elastomers (MRE). It is well known that both MRF and MRE are actively studied and applied to many practical systems such as vehicle dampers. The mandatory requirements for successful applications of MRF and MRE include several factors: advanced material properties, optimal mechanisms, suitable modeling, and appropriate control schemes. Among these requirements, the use of an appropriate control scheme is a crucial factor since it is the final action stage of the application systems to achieve the desired output responses. There are numerous different control strategies which have been applied to many different application systems of MRF and MRE, summarized in this review. In the literature review, advantages and disadvantages of each control scheme are discussed so that potential researchers can develop more effective strategies to achieve higher control performance of many application systems utilizing magneto-rheological materials.
\end{abstract}

\section{Keywords}

art, control, schemes, smart, systems, rheological, materials, featuring, state, magneto

Disciplines

Engineering | Science and Technology Studies

\section{Publication Details}

Choi, S., Li, W., Yu, M., Du, H., Fu, J. \& Do, P. Xuan. (2016). State of the art of control schemes for smart systems featuring magneto-rheological materials. Smart Materials and Structures, 25

043001-1-043001-24.

\section{Authors}

Seung-Bok Choi, Weihua Li, Miao Yu, Haiping Du, Jie Fu, and Phu Xuan Do 


\title{
A State-of-Art on Control Schemes for Smart Systems Featuring Magneto-Rheological Materials
}

\author{
Seung-Bok Choi ${ }^{1 *}$, Weihua $\mathrm{Li}^{2}$, Miao $\mathrm{Yu}^{3}$, Haiping $\mathrm{Du}^{4}$, Jie $\mathrm{Fu}^{3}$ and Phu Xuan Do ${ }^{1}$ \\ ${ }^{1}$ Smart Structures and Systems Laboratory, Department of Mechanical Engineering, \\ Inha University, Incheon 402-751, Korea \\ ${ }^{2}$ School of Mechanical, Materials and Mechatronic Engineering, \\ University of Wollongong, NSW 2522, Australia \\ ${ }^{3}$ Key Lab for Optoelectronic Technology and Systems, Ministry of Education, College of Optoelectronic \\ Engineering, Chongqing University, Chongqing 400044, China \\ ${ }^{4}$ School of Electrical, Computer and Telecommunication Engineering, \\ University of Wollongong, NSW 2522, Australia
}

*Corresponding Author: e-mail: seungbok@inha.ac.kr

Tel: +82-32-860-7319, Fax: +82-32-868-1716 


\begin{abstract}
This review article presents various control strategies for application systems utilizing smart magnetorheological fluid (MRF) and magneto-rheological elastomers (MRE). It is well known that both MRF and MRE are actively studied and applied to many practical systems such as vehicle dampers. The mandatory requirements for successful applications of MRF and MRE include several factors; advanced material properties, optimal mechanism, suitable modeling, and appropriate control schemes. Among these requirements, the use of appropriate control scheme is a crucial factor since it is a final action stage of the application systems to achieve desired output responses. There are numerous different control strategies which have been applied to many different application systems of MRF and MRE. This review article summarizes control strategies which have been successfully applied to MRF and MRE based application systems. In the literature review process, advantages and disadvantages of each control scheme are also discussed so that potential researchers can develop more effective control strategies to achieve higher control performance of many application systems utilizing magneto-rheological materials.
\end{abstract}

Keywords: Magneto-rheological Fluid (MRF), Magneto-rheological Elastomer (MRE), MRF Damper, MRE Isolation System, Skyhook Control, Optimal Control, Robust Control, Intelligent Control, Adaptive Control, Hybrid Control 


\section{Introduction}

Smart materials of MRF and MRE belong to a family of rheological materials that undergo rheological changes under the application of magnetic fields. Typically, these materials are composed of soft ferromagnetic or paramagnetic particles such as pure iron, carbonyl iron and cobalt powder. In the absence of a magnetic field, the particles are randomly distributed, but under the influence of an applied magnetic field, the particles acquire a dipole moment aligned with the external field and form chains. This chain formation induces a reversible yield stress of MRF and MRE. The yield stress is continuously and rapidly adjustable since it responds to the intensity of the applied magnetic field. As a result, MRF and MRE application systems or devices can have inherent advantages such as continuous controllability of dynamic range and fast response.

In general, the synthesis of high performance MRF and MRE application systems require several factors. First, advanced material properties must possess high yield stress at maximum magnetic fields and low viscosity in the absence of a field. Further, the MR effect should be stable within a wide temperature range. In addition to efforts to improve field-dependent yield stress, research on sedimentation, incompressibility, specific heat transfer property, wear aspect, fatigue property and lubrication characteristics need to be undertaken to aid commercial development of advanced MRF and MRE. Second, from the control perspective, the most important aspect to consider is the response time to the magnetic field. The time constant of MRF and MRE need to be quantitatively identified with respect to particle size, particle shape, viscosity of the base oil, conductivity of the particle and so on. The accurate determination of the time constant is key to establish a proper dynamic model which is used for controller design. Another crucial factor for successful MRF and MRE application systems is to properly choose an appropriate control scheme for a certain application mechanism. In other words, the output control performance of MRF and MRE application systems should be the best with the chosen controller under any environmental conditions. Despite the significance of the choice of an appropriate controller for MRF and MRE application systems, a full review article on the control strategies has not been reported so far, while several review articles on modeling of MR materials and dynamic modeling techniques of MR application systems have been introduced by several researchers [293302].

Consequently, this article reviews various control schemes which have been successfully applied to MRF and MRE devices and systems so far. In general, the control schemes used for MRF and MRE application systems can be classified into three types; classical controllers such as skyhook controller, advanced modern controllers such as adaptive controller, and hybrid controller strategies combining more than two different control strategies such as adaptive fuzzy sliding mode controller. The classical control methods include a skyhook controller, a sky-ground-hook controller and a proportional-integral-derivative (PID) controller. The salient feature of the classical controller is the simplicity for practical implementation with low cost. The advanced model control strategies include a sliding mode controller (SMC) and adaptive controller. The common feature of these controllers is the robustness of the control system against external disturbances and parameter uncertainties. The hybrid control strategies include a fuzzy sliding mode controller and an adaptive 
neural network controller. These controllers consist of more than two control schemes in order to improve control performance as well as maintaining robust stability against uncertainties. Specifically, in this review article the following controllers, which are frequently adopted for high performances of MRF and MRE systems, are introduced with application systems; skyhook controller, PID controller, optimal linear quadratic regulator/Gaussian (LQR/LQG), sliding mode controller, fuzzy controller, adaptive controller, neural network controller, H-infinity controller, and hybrid controller. In the review process, some inherent properties of each controller are addressed by presenting advantages and disadvantages for a certain application of MRF and MRE. This review article can provide very useful guidelines for the choice of appropriate control strategy corresponding to the dynamic characteristics of MRF and MRE application systems to achieve desired control responses. In addition, it is noted here that since many cars are currently running with MRF dampers on roads as given in Table 1, the publication of this review article one the control schemes is timely appropriate.

\section{Skyhook Controller}

The skyhook controller is the simplest control, but very effective in a semi-active control system associated with MRF and MRE. The configuration of the skyhook controller is shown in Figure 1 and its control input $(u)$ is defined as follows:

$u=G_{s} \dot{x}$

where $G_{s}$ is the control gain and $\dot{x}$ is the velocity of the system. The value $G_{s}$ for this controller is normally determined on the basis of a trial-and-error method. This parameter is a main factor to achieve high performance of control system. In general, this controller can provide favorable output responses in the absence of external disturbances and parameter variations. However, the disadvantage of the skyhook controller is the lack of robust stability in the presence of external disturbances and parameter variations. Since the control gain is not adjustable in the real time process, it may cause high energy consumption resulting in bad control performance. Despite the disadvantage, the skyhook controller is frequently adopted for MRF and MRE application systems due to its simplicity and cost effectiveness.

\subsection{MRF Damper}

One of the first applications of the skyhook controller is MRF seat damper [1]. In this study, the skyhook controller given in equation (1) has been modified by considering upward and downward motion of the seat damper. The test was undertaken in the frequency range from $0.4 \mathrm{~Hz}$ to $2.4 \mathrm{~Hz}$ under a bump excitation. It was shown through experiment that the vibration of the system can be significantly decreased using the skyhook controller. In addition, the acceleration after controlling has been satisfied to meet ISO 2631/85 requirement in the wide range of frequencies. On the other hand, Han et al. [2] proposed a vehicle damper utilizing an electro-rheological fluid (ERF). The ERF damper was used for primary suspension, and the MRF damper was used for seat. Two kinds of excitation were applied in this study such as bum and random roads. 
Because of the primary suspension, the skyhook controller of ERF damper was divided into two cases: for front suspension and for rear suspension following the velocity of the vertical direction of the vehicle. It has been demonstrated from experimental tests that the reduced vibration of displacement and acceleration were $45 \%$ and $30 \%$, respectively, comparing with the passive seat damper. It is noted that these reductions are enough to meet ISO 2631/85 requirement. Another study about MRF damper for suspension vehicle was presented in [3, 4]. The MRF damper proposed in this study was designed in flow mode and the skyhook controller was adopted to control unwanted vibration of a quarter car model. It has been shown through simulation that the acceleration in the frequency range up to $20 \mathrm{~Hz}$ between body resonance and wheel mode is effectively reduced showing improved ride comfort as well as steering stability due to the small tire deflection. Based on the original skyhook controller, some new modified skyhook controllers were also presented in [5]. In this work, a new controller based on the skyhook control concept called no-jerk skyhook controller was proposed. This controller is quite similar to the skyhook control, except that the damping coefficient is a function of both absolute and relative velocity. The no-jerk skyhook controller is defined as follows:

$u=\left\{\begin{array}{c}K\left|V_{1} V_{12}\right| \text { for } V_{1} V_{12} \geq 0 \\ 0 \quad \text { for } V_{1} V_{12}<0\end{array}\right.$

where $V_{1}$ is the absolute velocity of the sprung mass, $V_{12}$ is the relative velocity across the suspension, and $K$ is the constant gain. To evaluate the proposed controller, MRF seat damper system was used. Experimental results have shown that the new proposed no-jerk skyhook controller is better than the original sky-hook controller. However, the smooth dynamic of both controllers was identified to be similar by eliminating the discontinuity of damping force.

\subsection{Vehicle Suspension System}

A comparative work between the skyhook controller and the passive control action has been made by considering MRF vehicle suspension [6,7,8]. Control responses obtained from experiments have shown that the result of skyhook controller is much better than the passive one in terms of vibration control performances. In order to compare control performances among the skyhook controller, optimal LQG controller and sliding mode controller were adopted in a quarter car suspension model [9]. Through simulation with bump excitation, it was shown that the semi-active suspension controlled by the skyhook controller could effectively reduce the first peak-to-peak acceleration of the sprung mass and hence shorten the adjusting time. The displacement was also smaller than that with the passive control. In simulation with sinusoidal excitation, the performance of the skyhook controller was superior in the un-sprung mass resonance frequency range. Besides, the skyhook controller could improve the ride comfort under the random excitation. Compare with other controls, the skyhook control showed the best improvement in reduction of the sprung mass acceleration. However, because of the inherent nature of the skyhook controller, the control performance was not achieved for the un-sprung mass. Hence, it should be paid attention that the skyhook controller is not recommended for the road conditions such as speed bump. On the other hand, it could depress the vibration of sprung mass over 
$8 \%$ of peak-to-peak acceleration with the optimal controller (LQG) and the acceleration of the un-sprung mass could be effectively controlled by using both the skyhook controller and the sliding mode controller. It is known that the control scheme may depend on the dynamic model of the application system. A dynamic model of MR seat suspensions was developed by Song et al. [10]. In this context, two controllers including ideal skyhook control and ideal adaptive semi-active control were chosen to control unwanted vibrations. The ideal skyhook controller was based on no-jerk skyhook control as shown in equation (2), and the ideal adaptive semi-active controller was developed by using gradient search method. It has been demonstrated that the adaptive controller significantly improves the suspension performance over the skyhook controller. In addition, the power control of the adaptive controller was less than the skyhook controller, especially in the high frequency excitation. The ride comfort after controlling by adaptive controller was improved showing a smooth motion. Yao et al. [11] compared the skyhook controller with one of robust controllers, H-infinity controller by adopting MR seat suspension system. It has been shown via computer simulation that that $\mathrm{H}-$ infinity controller provides much better control performance than the skyhook controller. The skyhook controller was also used to compare the efficiency between passive damper and semi-active damper in [12, 14]. In this study, the skyhook controller, the ground-hook controller and the sky-ground controller were adopted and applied to railway vehicle to investigate lateral vibrations control performance. The ground-hook controller is defined as follows:

$$
\left\{\begin{array}{c}
-V_{2} V_{12}>0 \quad F_{\mathrm{d}}=G_{g} V_{2} \\
-V_{2} V_{12}<0 \quad F_{\mathrm{d}}=0
\end{array}\right.
$$

where $V_{2}$ is the absolute velocity of the un-sprung mass with respect to the ground, and $G_{g}$ is the gain factor of damping force. It has been shown from experiment results that the original skyhook controller can significantly reduce the transmissibility of the sprung mass, and the ground-hook controller can substantially reduce the un-sprung mass transmissibility. On the other hand, the combination of the skyhook controller and acceleration driven damping (ADD) control method was studied as a hybrid control strategy in [15]. It has been demonstrated that the hybrid controller yields very good performance in terms of both stiffness and damping ratios showing significant reduction of vertical acceleration and displacement at the same time.

\subsection{Other Applications}

The skyhook controller was also applied to evaluate vibration control performance of MR landing gear in [8]. The skyhook controller was designed based on the simplified model and its control results were compared with min-max control method (passive control). It has been shown that the skyhook controller provides better performance with less energy than the min-max control method. The original skyhook controller given in equation (1) was applied to MR damper-mount, which was proposed for vibration control of the ultraprecision manufacturing system [16]. The skyhook controller was implemented and its control results were compared with the results obtained from the sliding mode controller. Evaluation results showed that both controllers provided very similar vibration control performance, but the control performance was not good with the sign function of the sliding mode controller due to the undesirable chattering behavior. The 
combination of two controllers such as fuzzy control and skyhook control was presented by Cho et al. [7]. In this study, the fuzzy control and the skyhook control were combined as a fuzzy-skyhook control, and applied to MR damper system subjected to impact loads. Results of simulation showed that the fuzzy-skyhook control scheme provided better control performance than the one obtained from each controller. In order to evaluate the vibration control performance of MR damper and MR elastomer, the skyhook controller was used in [13]. In this work, each device was evaluated firstly, and combined damper-elastomer was evaluated. It has been identified that the use of the combination of MR damper and MR elastomer shows much better performance in vibration control than the use of each damper or elastomer. There are lots of research work on the applications of MRF and MRE using the skyhook controller. These studies have been undertaken from both computer simulation $[3,4,6,7,8,10,11,15,17]$ and experimental implementation $[1,2,5,9,12,13,14,16]$.

\section{PID Controller}

Similar to the skyhook controller, the scheme of the proportional-integral-derivative (PID) controller is very simple and effective. This leads that PID controller is a standard control tool for industrial automation [18]. Because of its flexibility, the PID controller can be used for either cascade control scheme or other configuration control scheme. The definition of PID control is expressed as follows [18]:

$u_{P I D}=K_{P} e(t)+K_{I} \int_{0}^{t} e(\tau) d \tau+K_{D} \frac{d e(T)}{d t}$

where $u_{P I D}$ is the control variable, $e$ is the error defined as $e=u_{r}-y$, where $u_{r}$ is the reference value, and $y$ is the process output. $K_{P}, K_{I}, K_{D}$ are the control gains for the proportional, integral and derivative control action, respectively. A typical block-diagram of the PID controller is shown in Figure 2. Its control performance depends heavily on the values of control gains. Therefore, the right choice of the control gain of each actuation action is very significant to achieve favorable control performance of dynamic systems, especially semi-active dynamic systems featuring MRF and MRE.

\subsection{Vehicle Suspension System}

The damping force control performance using the skyhook controller and PID controller were evaluated by adopting the semi-active vehicle suspension system installed with a MRF damper in [19]. In this work, the combination of the skyhook and PID controllers was also considered to control damping force of MR dampers. Based on equation (4), the PID controller was modified as follows:

$$
u=k_{P} e+k_{I} \int e+k_{D} \dot{e}
$$

where $e=F_{d}-F_{a}, k_{P}$ is the proportional feedback gain, $k_{I}$ is the integral feedback gain, $k_{D}$ is the derivative feedback gain. $F_{a}$ is the actual damping force and $F_{d}$ is the desired damping force. It has been 
shown that both vertical displacement and acceleration are substantially decreased by activating the PID controller associated with MR dampers. In addition, the angular displacement and angular acceleration are also reduced using the proposed PID controller and the hybrid controller consisting of the skyhook controller and PID controller. These results directly indicate the increment of both ride quality and steering stability of the vehicle suspension system by activating PID controller associated with MRF damper actuators. Following this hybrid control trend, a combination of a H-infinity technique method and a PD controller was suggested in [20]. The proposed controller was applied to MR suspension system in which the H-infinity-PD control served as the system controller to provide the desired damping force. A fuzzy-PID control based on the combination of the fuzzy logic control and the PID controller was studied in [21]. The controller was applied to suspension of vehicle featuring MRF dampers. It has been demonstrated from experimental results that the fuzzy-PID control can decrease unwanted vibrations much more than using the PID controller only. The rate of decreasing of the combined controller has been improved over 50\% comparing with the PID controller only.

\subsection{Other Applications}

It is known that PID controller is very suitable for circular motion control due to its inherent advantage in tracking the initial trajectories. One of the most general circular motion systems is the brake. The cylindrical type of MRF brake was proposed in [22]. In this study, a PID controller was integrated with the hysteresis compensator to improve control accuracy. It is remarked that when the PID controller is integrated with the feed-forward hysteresis compensator, the determination of control gains of the PID controller is very crucial to avoid hardware destroy due to very high control energy. Another study using a PID controller to evaluate a new design of MR actuator for circular motion was presented in [23]. In this work, a torque transfer device was introduced and its torque transmission was evaluated by implementing the PID controller. It has been shown from experimental investigation that the PID controller can provide favorable control response to the fixed torque values, but cannot follow the time-varying torque values. Besides of the above addressed applications, there are also other applications of PID controllers. The tracking control using a PID controller was also presented in [24]. In this work, a 4-DOF MR haptic master was proposed and its trajectory tracking ability was evaluated by realizing a PID controller. It has been shown from experimental implementation of the PID controller that the tracking performances for sinusoidal profile can be successfully achieved, but the relatively large tracking error can be occurred for complicated trajectory tracking motions. From the literature survey on PID control strategies for MRF and MRE application systems, it has been identified that using PID controller only exhibits some limitations to get superior and robust control performances. Hence, in most of application systems, the combination control strategies between a PID and other control schemes such as $\mathrm{H}-$ infinity controller were used for MRF and MRE application systems to achieve high-efficiency in control operation. It is remarked here that in most of MRF and MRE applications the PID controller has been experimentally realized as presented in $[19,21,22,23,24]$.

\section{Optimal Controller}


Optimal control strategy can be divided into two schemes: linear quadratic regulator (LQR) control method and liner quadratic Gaussian (LQG) control method as shown in figure 4(a) and 4(b), respectively. As a first step to formulate optimal controller, consider the following linear dynamic system:

$$
\dot{x}=\mathbf{F}(t) x+\mathbf{G}(t) u, x\left(t_{0}\right) \text { given }
$$

In the above, $\boldsymbol{x}$ is the state, $\mathbf{F}(t)$ and $\mathbf{G}(t)$ are assumed continuous and suppose the matrices $\mathbf{Q}(t)$ and $\mathbf{R}(t)$ have continuous entries, be symmetric, and be nonnegative and positive definite, respectively. By supposing $\mathbf{A}$ be a nonnegative definite matrix, the following index is formulated [25]:

$V\left(x\left(t_{0}\right), u(),. t_{0}\right)=\int_{t_{0}}^{T}\left(u^{\prime}(t) \mathbf{R}(t) u(t)+x^{\prime}(t) \mathbf{Q}(t) x(t)\right) d t+x^{\prime}(T) \mathbf{A} x(T)$

where $T$ is the finite time. Then, the minimal value of the performance index is given by

$V *\left(x\left(t_{0}\right), t_{0}\right)=x^{\prime}\left(t_{0}\right) \mathbf{P}\left(t_{0}, T\right) x\left(t_{0}\right)$

where $\mathbf{P}\left(t_{0}, T\right)$ is the solution of the following Riccati equation:

\section{$-\dot{\mathbf{P}}=\mathbf{P F}+\mathbf{F}^{\prime} \mathbf{P}-\mathbf{P G R}^{-1} \mathbf{G}^{\prime} \mathbf{P}+\mathbf{Q}$}

In the above, $\mathbf{P}(T, T)=\mathbf{A}$ is the boundary condition to solve equation (9). Now, LQR optimal controller is formulated as follows:

$u^{*}(t)=-\mathbf{R}^{-1} \mathbf{G}^{\prime}(t) \mathbf{P}(t, T) x(t)$

The derivation method of the LQG optimal controller is very similar to the LQR controller. In fact, the LQG controller is the combination of the Kalman filter and the LQR controller. It is remarked that the Kalman filter is also called as linear quadratic estimator (LQE). In order to formulate a LQG controller, consider the following linear system:

$\dot{x}=\mathbf{F}(t) x+\mathbf{G}(t) u+\mathbf{w}, x\left(t_{0}\right)$ given

where $\mathbf{w}$ is additive white Gaussian noise. The measurement system is then modeled as follows:

$y=\mathbf{H} x+\mathbf{v}$

In the above, $\mathbf{v}$ is output measurement noise. Now, the performance index for the LQG controller is defined as follows [26]:

$$
J=e\left\{\frac{1}{2} x^{T}(T) \mathbf{S} x(T)+\frac{1}{2} \int_{0}^{T}\left(x^{T} \mathbf{Q} x+u^{T} \mathbf{R} u\right) d t\right\}
$$


In the above index, $e$ is the expected value. The system of equations that defines the optimal Kalman filter is given by

$\dot{\hat{x}}=\mathbf{F}(t) \hat{x}+\mathbf{G}(t) u+\hat{\mathbf{K}}(y-\mathbf{H} \hat{x})$

where $\hat{\mathbf{K}}=\hat{\mathbf{P}} \mathbf{H}^{\prime} \hat{\mathbf{R}}^{-\mathbf{1}}$, and $-\dot{\hat{\mathbf{P}}}=\hat{\mathbf{P}} \mathbf{F}+\mathbf{F}^{\prime} \hat{\mathbf{P}}-\hat{\mathbf{P}} \mathbf{G} \hat{\mathbf{R}}^{-\mathbf{1}} \mathbf{G}^{\prime} \hat{\mathbf{P}}+\mathbf{Q}$. The LQG control problem is then solved by the following equations:

$$
\dot{\hat{x}}=\mathbf{F}(t) \hat{x}+\mathbf{G}(t) u
$$

Then, the objective performance index can be written by

$$
J=\frac{1}{2} \hat{x}^{T}(T) \mathbf{S} \hat{x}(T)+\frac{1}{2} \int_{0}^{T}\left(\hat{x}^{T} \mathbf{Q} x+u^{T} \mathbf{R} u\right) d t
$$

Now, the LQG optimal controller is formulated using the estimated states as follows:

$$
u(t)=-\mathbf{R}^{-1} \mathbf{G}^{\prime}(t) \mathbf{P}(t, T) \hat{x}(t)
$$

\subsection{Vibration Control of Flexible Structures}

The optimal LQR controller associated with MRF damper was applied to flexible truss structures for vibration control [29]. The MR damper in this application was designed by using a permanent magnetic, and the damping force was varied following the exciting force of truss structure. It has been shown from experimental results that the excited vibration of the structure is effectively controlled by activation MRF damper integrated with LQR controller. This controller was then modified by considering the semi-active actuating condition and applied to the same truss structure [30]. It has been identified that the modified LQR can provide better vibration control performance than the original $L Q R$ controller which is not connected to the semi-active actuating condition. In order to control unwanted vibration of bridge cable, the original LQR/LQG controller associated with MRF damper was applied in $[31,36]$. The LQR controller was designed as the statederivative feedback control for MRF damper [31] and inversely, the combination of LQR and LQG controls was employed in [36] in which LQR controller was used to determine the optimal force for the system while the LQG controller was used to calculate the optimal force in an ideal active actuator. It has been shown from experimental results that the optimal $\mathrm{LQR} / \mathrm{LQG}$ controller can reduce unwanted vibrations of the cable system by activating MRF damper. The LQG controller was also used in vibration control for building systems in [39]. The proposed controller was designed on the basis of the linear matrix inequality (LMI) control scheme. In addition, the $\mathrm{H}_{2}$ control was also used in this context and combined to the LQG controller. It has been demonstrated that the optimal LQG controller based on LMI can provide much better vibration control performance than the $\mathrm{H}_{2} / \mathrm{LQG}$ controller. Another vibration control of the benchmark building was 
carried out in [43] in which two MRF dampers were used and the LQR controller was used to find optimal force required for the vibration control. It has been shown that the use of the optimal LQR controller exhibits much larger vibration reduction than the conventional passive control method. In order to control the vibrations of beam structures, the optimal LQR controller was designed using a MRF damper in [40]. It has been shown that the full-state observer based the LQR controller was effective in vibration control. A clipped optimal controller was also suggested to control vibrations of civil engineering structures using a MRF damper in [42]. The proposed control was established by using LQG control strategy and effectively realized for reduction of both acceleration and displacement of the beam structure.

\subsection{Other Applications}

Since the optimal controller is relatively easy to empirically easy due to the linearity, there are many application systems using MRF and MRE. Modeling and control of MRF damper using LQG was presented in [27]. The clipped-optimal control based on LQG control method was applied to control seismic vibration by activating MRF damper. It was shown that the control force of the clipped-optimal control was lower than passive controller, but its vibration control performance was better. The combination of the LQR controller and neural networks control method was applied to MRF damper in [28]. In this application, the LQR control was used with two inverse neural network models of MRF damper. The neural networks included forward and inverse neural networks. It has been shown that the desired damping force is successfully achieved by the proposed hybrid controller. Another study of the combination between LQR controller and neural networks controller for MRF damper was presented in [34]. The role of LQR optimal controller was to achieve optimal force control which was the output of inverse dynamic model. It has been demonstrated that the inverse model is not suitable for damping force tracking control of MRF damper. The combination of LQG controller and neuro-fuzzy controller was also applied to MRF damper in which the adaptive fuzzy neuron inference system (AFNIS) was used [38]. The role of the LQG controller was to obtain the training data for the AFNIS algorithm. It has been shown that the combined controller associated with AFNIS can provide better control performance than the LQG controller only. The application of LQR/LQG control to MRF suspension was also carried out in many groups [33, 41, 44, 45, 46, 47]. Vibration of high-order degrees of freedom suspension system using MRF damper was presented in [41]. In this study, the model of neuro-fuzzy control technique was used and its outstanding performance was compared with LQR and LQG control performance. The LQG controller using the acceleration feedback was used in control of railway suspension system in $[44,45,46]$. The 17-degree-of-freedom model of railway vehicle was applied in this study, and MRF damper was used as the main suspension component. A human simulated intelligent control for vehicle suspension featuring MRF damper was presented in [47]. The proposed controller was developed to attenuate unwanted vibrations and its results obtained from both simulation and experiments were compared with conventional LQG control strategy. It has been concluded that the vertical vibration and pitch motion of vehicle can be significantly reduced after activating the proposed controller associated with MRF damper. The optimal LQG controller was also applied in the performance evaluation of MRF mount system in [32]. It was shown that the unwanted vibration level was decreased effectively by the semi-active MR mount. Another optimal control for the mixed MRF mount system was presented in [37] in which the optimal LQG controller was used for successful 
vibration control by activation MRF mount. In literature, a large number of simulation studies [27, 33, 34, 35, $38,39,40,41,42,43,44,45,46]$ and experimental work [28,29,30,31,32,36,37,47] were conducted to investigate the optimal control performances. It is remarked here that the combination of LQR control and other control strategies such as neural network, fuzzy-neural network and $\mathrm{H}_{2}$ technique is very popular.

\section{Sliding Mode Controller}

Despite many advantages of PID controller and optimal controller, there exist some system perturbations (uncertainties) associated with MRF and MRE devices and systems. For instance, the field-dependent yield shear stress of MR fluid is subjected to change according to temperature variation. Moreover, the dynamic behavior of MRF device is a function of a magnetic field. There may also exist nonlinear hysteresis of the damping force in MRF damper. Therefore, in order to guarantee control robustness of the control system featuring MRF and MRE systems, a robust controller needs to be implemented to take account for system uncertainties. A sliding mode controller (SMC), also called variable structure controller, is well known as one of the most attractive candidates which assures control robustness against system uncertainties and external disturbances. The sliding mode control systems have invariance properties to the parameter variations and external disturbances under the sliding mode motion. A concept of a sliding mode control is depicted in Figure 4. In the figure, $s$ is sliding surface function, $u_{s w}$ is switching function, sat is saturation function for preventing the chattering phenomenon. It is noted that the control $u$ is synthesized from the main control function of the system and switching function. In order to derive a simple SMC, consider the second-order system subjected to the external disturbance:

$$
\begin{aligned}
& \dot{x}_{1}=x_{2} \\
& \dot{x}_{2}=a x_{1}+x_{2}+u+d
\end{aligned}
$$

where $d$ is external disturbance and $a$ is the parameter variation. They are bounded by

$$
|d| \leq \varepsilon, \quad a_{1} \leq a \leq a_{2}
$$

As a first step, we choose a stable sliding line as follows [48]:

$$
s_{g}=c x_{1}+x_{2}=0, \quad c>0
$$

Then, derivative of the sliding mode motion can be obtained as follows:

$$
\dot{s}_{g}=c x_{2}+a x_{1}+x_{2}+u
$$

Thus, SMC, $u$, can be designed as follows to satisfy the sling mode condition given in equation (23).

$$
\begin{aligned}
& u=-c x_{2}-x_{2}-a_{0} x_{1}-\left(k+\left|a_{m}\right|\left|x_{1}\right|\right) \operatorname{sgn}\left(s_{g}\right), \\
& k>\varepsilon, \quad a_{0}=\left(a_{1}+a_{2}\right) / 2, \quad a_{m}=a_{2}-a_{0}
\end{aligned}
$$

The sliding mode condition to guarantee the stability of the control system can be satisfied as follows: 


$$
s_{g} \dot{s}_{g}=\left(a-a_{0}\right) x_{1} s_{g}-\left(k+\left|a_{m}\right|\left|x_{1}\right|\right)\left|s_{g}\right|<0
$$

The design procedures of SMC can be easily extended to higher order control systems without any difficulty.

\subsection{Vehicle Suspension System}

Since the vehicle suspension has several uncertainties such as mass variation due to the number of passenger, the sliding mode controller is effectively utilized to achieve robust control performance. In order to improve ride comfort, SMC was used for the vehicle suspension system equipped with MRF dampers [49]. In this study, all of state variables were assumed to be available for designing SMC and directly applied to control the desired damping force. Another study applying SMC to suspension vehicle was presented in [50] in which the observer sliding mode was established from the original model and the saturation function was used instead of the sign function to prevent the chattering phenomenon. In addition, the skyhook control and passive control were also used to compare with the proposed SMC. It has been shown that the proposed SMC can provide better ride quality than the skyhook controller. The original sliding mode controller combined with fuzzy control logic was studied in [52] where the simple Takeki-Sugeno model was used as the fuzzy model. An adaptive sliding mode controller based on fault tolerant for MR suspension was studied in [54]. In this work, the fault tolerant model was established by modifying two stage adaptive Kalman filtering algorithm.

\subsection{Other Applications}

Besides of application in vehicle suspension systems, SMC was also applied to brake and mount systems associated with MRF and MRE. The original sliding mode control was applied MRF brake for optimal wheel slip control in [51]. It has been shown that the potential of the proposed SMC is guaranteed showing the robust stability of the brake system subjected to several road uncertainties. A combination of the fuzzy logic control and sliding mode control was presented in $[56,59]$ for improvement of robust control performances of MRF rotary damper and MRF mount. Recently, SMC was also used in [60] for control torque trajectory of the haptic master-slave robot system. It has been demonstrated that an accurate tracking control performance can be achieved from the proposed control scheme. The conventional sliding mode controller was also applied to MRF damper for vibration control of the bed stage [61]. A modified sliding mode controller in switching surface for MRF damper was presented in [53] where the switching surface was modified to follow the damping force of the system SMC was compared with original PID controller using MR squeeze film damper in [58]. It has been identified that SMC can provide stronger robustness of the system under disturbances of PID controller. Besides the above application systems of SMC, there are a great number of experimental studies [53,54,55,56,57,59,60,61] and computer simulations [49,50,51,52,58,62]. It is noted that the combination of SMC with other control schemes such as neural network algorithm can improve control performance of MRF and MRE systems better than using SMC only under uncertain environmental conditions. 


\section{Fuzzy Controller}

It is well known that the fuzzy logic has the characteristic of inherent robustness, the ability of handling nonlinearities and uncertainties, and do not require a precision mathematical model, and hence it has attracted the attention of researchers and engineers during the last few years [80-83]. Fuzzy-set theory was proposed in $[84,85]$, and then has been successfully applied to a diverse range of applications, mostly in the fields of control and intelligence system [86,87]. Fuzzy control provides a formal methodology for representing, manipulating, and implementing a human's heuristic knowledge about how to control a system. There are four main components in fuzzy controller as shown in Figure 5: (1) fuzzification, (2) inference mechanism, (3) rule-base, (4) defuzzification. The critical parameters of designing the fuzzy controller are membership functions, the inference mechanism and algorithm, and the defuzzification algorithm. In a general fuzzy logic control (FLC), the scaling factor is constant. But in a real system, the maximum of input is uncertainty, and hence how to choose an appropriate scaling factor is significant. The objective of "membership function" is quantifying the meaning of the linguistic. The labels of membership functions are often as follows: NL refers to negative large, NM to negative medium, NS to negative small, $\mathrm{Z}$ to zero, PS to positive small, PM to positive medium, and PL to positive large. For example, the membership function quantifies, in a continuous manner, whether values of input belong to the set of values are NL. The membership functions including a trapezoid-shaped function, a Gaussian, a triangle, a bell and so on. The triangle and trapezoid function are consist of straight line, and they have simply algorithm and often been chosen in real system. It is called $\mu(x)$ is the degree of membership which corresponds to the input $x$. The Gaussian function is also often chosen in simulation system because of its smooth. The formula of Gaussian is expressed as follows:

$\mu(x)=\exp \left(-\left(\frac{x-a}{\sigma}\right)^{2}\right)$

where $\mu(x)$ is the degree of membership which corresponds to the input $x, a$ and $\sigma$ are the parameters which decided the center and width of the Gaussian function, respectively. To get an excellent result, it is benefit to combine the different membership function or iteratively adjust the membership functions according to a given set of input and output data [89]. In the fuzzy logic controller, the inputs and outputs are often related by a set of well-established rules such as "If ...then". The system model is described by "If ...then" fuzzy rules [89] which the number is $q$

If $x_{1}$ is $A_{i}^{k}$ and $x_{2}$ is $B_{i}^{k}$ Then $y$ is $C_{r}^{k}(k=1,2, \ldots, q)$

where $x_{1}$ and $x_{2}$ are the inputs of system, $y$ is the output of system. $A_{i}^{k}$ and $B_{j}^{k}$ denote the $i^{\text {th }}$ and $j^{\text {th }}$ antecedents of $x_{1}$ and $x_{2}$, respectively, of the $k^{\text {th }}$ rules, $C_{r}^{k}$ denotes the $r^{\text {th }}$ consequent of $y$. The algorithm of fuzzy model is depicted as follows: 
$U_{R}\left(x_{1}, x_{2}, y\right)=\vee_{i=1, j=1}^{i=k, j=l} \mu_{x 1 i}(a) \wedge \mu_{x 2 j}(b) \wedge \mu_{i j}(c)$

where $U_{R}\left(x_{1}, x_{2}, y\right)$ is the output degree of membership, $\mu_{x 1 i}(a)$ and $\mu_{x 2 j}(b)$ are the degree of membership of $x$ and $y$, respectively. $\mu_{i j}(c)$ denotes the degree of membership of the conclusion based the fuzzy rules. $\wedge$ and $\vee$ is the Zadeh operators; denotes the minimum and maximum, respectively.

Defuzzification is converting the fuzzy set information produced by the inference process into numeric fuzzy controller outputs. The methods of defuzzification include center of gravity, center-average, max criterion, mean of maximum and center of area. The center of gravity (COG in short) is more common, a crisp output $y$ is chosen using the center of area and area of each implied fuzzy set, and is given by [88]:

$y=\frac{\sum_{i=1}^{R} c_{i}^{q} \int_{y} \mu_{\hat{C}_{i}^{l}}(y) d y}{\sum_{i=1}^{R} \int_{y} \mu_{\hat{C}_{i}^{l}}(y) d y}$

where $R$ is the number of rules, $c_{i}$ is the center of area of the membership function of $C_{q}^{p}$ associated with the implied fuzzy set $\hat{C}_{q}^{i}$ for the $i^{\text {th }} \operatorname{rule}(j, k, \ldots, l ; p, q)_{i}$, and $\sum_{i=1}^{R} \int_{y} \mu_{\hat{C}_{i}^{l}}(y) d y$ denotes the area under $\mu_{\hat{C}_{q}^{i}}(y)$.according to the formula, the area under each implied fuzzy set must be computable, and the fuzzy system must be defined so that $\sum_{i=1}^{R} \int_{y} \mu_{\hat{C}_{i}^{l}}(y) d y \neq 0$

\subsection{Vehicle Suspension System}

MR dampers are semi-active control devices that employ MR fluids to produce controllable damping force [90]. Because of the MRF damper's intrinsic nonlinear behavior, the fuzzy logic control was widely used in varies semi-active control systems [91]. A design of semi-active suspension with fuzzy controller through the use of a quarter car model was undertaken [92]. Both the simulation and experimental results demonstrated that the controller is very effective. Yu et al. [93] presented the implementation of a quarter-car fuzzy intelligent controller to control the two MRF independent suspension systems. Compared with the passive system, the root mean square (RMS) acceleration of the sprung mass is reduced by 6\%. Dong et al. [94] used four MR dampers to replace the passive ones of vehicle. With the fuzzy control, the RMS of the acceleration of sprung mass and unsprung mass at $40 \mathrm{~km} / \mathrm{h}$ is reduced by $4.60 \%$ and $9.01 \%$, respectively. Similar effectiveness was report by a number of groups [95-98] in simulation the system responses while being implemented a fuzzy-PID controller for semi-active vibration with MRF dampers. The membership functions and rules of general fuzzy control are constant in the control process but the excitation of the vehicle is random and complexity, the performance of control can be reduced. Atray and Roschke [97] used the neuro- 
fuzzy control in semi-active suspension with MR damper and the neuro algorithm was used to learn and optimize the membership functions. According to the simulation, the absolute peak of acceleration at Threequarter loaded has been reduced from 0.95 to 0.68 . Hashiyama et al. [98] used the genetic algorithm (GA in short) operations to optimize the number of fuzzy rules and parameters for membership functions, and it has been shown that the performance is improved a lot.

\subsection{Building Structural Control System}

Because of the low power consumption and high efficiency, MRF damper is widely used in the building structural control system. Zhou [99] reported a fuzzy semi-active control strategy for seismic response reduction using a MRF damper in the ship lift. Compared to the passive structure, the results of the simulation analysis shows the story drift reduced by $66.8 \%$, and the maximum lateral interlayer velocity and acceleration at the top of works shop reduced $39.0 \%$ and $17.5 \%$ respectively. In order to enhancing the Robustness of system under different excitations, Wilson and Abdullah [100] proposed a self-tuning fuzzy controller to reduce the structural responses of single degree-of freedom seismically excited structures. They adjusted the values of one or more of the scaling factors according to the change of the input variables to the fuzzy controller by using a fuzzy decision making system. Xu and Guo [101] proposed a neural-fuzzy control strategy applied in a three-story reinforced concrete structure. The neuro-network was used to solve the timedelay problem to acquire the accuracy value, while the fuzzy control to determine the control current of MR dampers. Gu and Oyadiji [102] also proposed an adaptive neural-fuzzy inference system in the multipledegree-of-the freedom building structures. The membership functions of the fuzzy logic was iteratively adjusted according to a given set of input and output data by neuro-network training. The displacement of 1 th floor has been reduced by $78 \%$ with simulation, in the Excitation of EI Centro earthquake. Yan and Zhou [103] presented a control strategy based on GA for semi-active fuzzy control of structures, and the GA was used as an adaptive method to change the fuzzy control rules and the other parameters and membership functions were chosen by constant. By changing, adding and deleting rules, the GA automatically can adapt and optimize the fuzzy control system. Bitaraf, et al. [104] and Shook et al. [105] presented a GA-fuzzy control for seismic protecting buildings with MR dampers, the non-dominated sorting genetic algorithm version II (NSGA-II) was employed to determine the rule set of the fuzzy logic controller. It has been shown that the peak absolute of acceleration, displacement and inter-story drift is reduced by $36 \%, 42 \%$ and $38 \%$, respectively. The base isolation is one of the most widely used and accepted in seismic protection system. Because of the wide range of seismic, the semi-active base isolation system with MRF damper was proposed in [106]. Jung et al [107] used the fuzzy logic control in smart base-isolated building with MRF damper. The displacement and velocity in base-isolated level were chosen as the input variables of fuzzy control while the damper force was chosen as the output variable. The fuzzy control showed the reliable performance for the all seven different earthquakes. Lin et al [108] also used the fuzzy control in the hybrid base-isolation system which consists of high damping rubber bearings and MRF damper. Simulation results showed that both the displacement and acceleration of base were effectively reduced, simultaneously. Because the selection of membership function of the general FLC was subjective and time-consuming, Kim and Roschke [109-111] used the neuro-network or GA algorithm with the MRF damper in the hybrid isolation system which consists 
of the friction pendulum system (FPS) and MRF damper. Simulation results demonstrated that the fuzzy control with GA can not only reduce the structural acceleration but also reduce the base drift. .

\section{Adaptive Controller}

Several control algorithms have been adopted in application systems featuring MRF and MRE such as bangbang control [112-114], clipped optimal control [115,116], skyhook control [117-119], fuzzy control [120122], and neural network control [123-125]. However, the system uncertainties resulted by modelling errors, variation of materials properties, component non-linearity, and changing load environments can cause instability or performance degradation of above controllers [126-128]. To achieve satisfactory control effect, the adaptive controller has been designed, the parameters of which can be adjusted or tailored to the unknown or varying characteristics of the MRF and MRE systems [129]. An adaptive controller is a controller with adjustable parameters and a mechanism for adjusting the parameters. An adaptive control system has two loops: One is a normal feedback with the plant and the controller, and the other one is the parameter adjustment loop as shown in Figure 6. According to the different parameter adjustment mechanisms, there are mainly two types of adaptive controller: model reference adaptive system and self-tuning regulator. The model reference adaptive system consists of four parts: a plant which contains unknown parameters, a model which characterizes the desired command-response behavior of the system, a controller which contains adjustable parameters, and an adjustment mechanism which updates the adjustable parameters. The key issue in model reference adaptive system design is to obtain an adjustment mechanism which guarantees that the control system remains stable and the tracking error converges to zero as the parameters are varied [131]. The gradient update and Lyapunov theory are two representatives of the formalisms. Figure 7 shows a block diagram of a gradient update system. $k_{p} G(s)$ is the plant, $k_{m} G(s)$ the model, $k_{c}$ the controller, $G(s)$ the known transfer function, $k_{p}$ the unknown gain, $k_{m}$ the desired gain, and the output error $e(t)=y_{m}-y_{p}$.

Let the performance index function is $J\left(k_{c}\right)=\frac{1}{2} e^{2}(t)$. The idea behind the gradient update is to reduce $J\left(k_{c}\right)$ along the direction of steepest descent;

$$
\dot{k}_{c}=-\lambda \frac{\partial J}{\partial k_{c}}=-\lambda \frac{\partial J}{\partial e} \frac{\partial e}{\partial k_{c}}=\lambda e(t) \frac{\partial y_{p}}{\partial k_{c}}, \lambda>0
$$

where $\frac{\partial y_{p}}{\partial k_{c}}$ is defined as sensitivity derivative;

$$
\begin{aligned}
& E(s)=\left(k_{m}-k_{c} k_{p}\right) G(s) y_{r}(s) \\
& e(t)=\left(k_{m}-k_{c} k_{p}\right) G(p) y_{r}(t)
\end{aligned}
$$


In the above,

$$
\begin{aligned}
& p=\frac{d}{d t}, \frac{y_{m}}{y_{p}}=\frac{k_{m}}{k_{c} k_{p}}, y_{p}=\frac{k_{c} k_{p}}{k_{m}} y_{m}, \frac{\partial y_{p}}{\partial k_{c}}=\frac{k_{p}}{k_{m}} y_{m}, \dot{k_{c}}=\lambda e(t) \frac{k_{p}}{k_{m}} y_{m}=\mu e(t) y_{m} \\
& y_{m}=k_{m} G(p) y_{r}(t) \\
& y_{p}=k_{c} k_{p} G(p) y_{r}(t)
\end{aligned}
$$

where $\mu=\lambda \frac{k_{p}}{k_{m}}$ is adaptive gain. A block diagram of the self-tuning regulator is shown in Figure 8. It consists of four parts: a plant which contains unknown parameters, a parameters identifier which identifies the plant parameters, a controller which contains adjustable parameters, and a controller design block which updates the controller parameters based on the identification result and relationship between plant parameters and controller parameters. The self-tuning regulator is very flexible with respect to its choices of controller design methodology and identification scheme. Many different controllers such as LQR controller could be employed in self-tuning regulators, and three different parameter estimators (gradient estimator, least squares estimator and Lyapunov-based estimator) are normally used. Consider a linear system model given by

$$
y_{p}(t)=\phi(t) \theta(t)
$$

where the n-dimensional vector $y_{p}(t)$ contains the outputs of the system, the m-dimensional vector $\theta(t)$ contains unknown parameters to be estimated, and the $\mathrm{n} \times \mathrm{m}$ matrix $\phi(t)$ is the signal matrix. The estimator follows

$$
\hat{y}_{p}(t)=\phi(t) \hat{\theta}(t)
$$

In the above, $\hat{y}_{p}(t)$ is the output of the estimator and $\hat{\theta}(t)$ is the estimation value of the unknown parameters. And the estimation error is then given by

$$
e(t)=\hat{y}_{p}(t)-y_{p}(t)
$$

Therefore, using the Lyapunov-based model parameters estimator [140] the adaptive controller can be designed as follows:

$$
u(t)=k_{f}(t) r(t)+k_{b}(t) y_{p}(t)
$$

In the above, the gains $k_{f}(t)$ and $k_{b}(t)$ are adjustable parameters which satisfy the Lyapunov stability.

\subsection{MRF Damper}


Practical applications of MRF and MRE systems are frequently subjected to several uncertainties such as sudden temperature change. For example the increment of temperature will lead to the reduction of the fielddependent characteristics of MRF damper. However, the real-time temperature in the inner space of MR damper is hard to acquire. Dong et al. [175] proposed an adaptive sliding mode fault-tolerant controller to eliminate temperature induced practical fault of MRF damper. The controller was verified through computer simulation, and the scenario was the reduction of the control effectiveness in the front-right MRF damper at $0.55 \mathrm{~s}$. It has been demonstrated that the output damping force of the MR damper with reconfiguration is much bigger than the one without reconfiguration, and the peak-peak displacement control performance is improved by $43.41 \%$. A novel model of the controller was built based on adaptive hybrid control of interval type 2 fuzzy controller incorporating with a new modified sliding mode control [176]. The interval type 2 fuzzy was optimized for computational cost by using enhanced iterative algorithm with stop condition, a new modified switching surface of sliding mode control was designed for preventing the chattering of the system, and the adaptation law was derived by the Lyapunov theory. Two existing controllers from [186] and [187] were modified to undertake a comparative work. Both computer simulation and experiment results showed that the proposed controller had the best robustness and vibration control performance. Guo and $\mathrm{Hu}[177$, 178] designed direct and indirect adaptive neural network controller for the semi-active vehicle suspension system with MR damper. In their work, the error between identifier output and plant output was used to train the identifier in both controllers. The results of computer simulation and experiments in time-domain and frequency-domain demonstrated the advantages of the proposed controller over the passive suspension and the indirect adaptive neural network controller outperformed the direct one. The adaptive neural network controller proposed by Yang et al. $[179,180]$ was similar to the direct adaptive neural network. Computer simulation verified that the controller had a certain adaptability to the external disturbance, and the improvement in vibration control effect of adaptive controller with respect to the passive one was $45.64 \%$ at most. Laflamme et al. [181-183] proposed an adaptive neural network controller for mapping the behavior of civil structures controlled with MRF dampers. The structural response and the actual forces from the dampers were used to adapt the network by tuning the weights, centers and bandwidths. The weights, centers and bandwidths of the network were adaptive, and their adaptation laws were derived based on the Lyapunov stability theory. Zheng et al. [134] adopted the sky hook damper as the reference model and designed a model reference adaptive controller for semi-active suspension system. It has been shown that the proposed model reference controller can achieve good robustness against model uncertainties and is effective in ride and handling characteristics improvement. Song et al. $[129,146]$ developed an adaptive control algorithm to avoid the negative impact of the super-harmonics introduced by the skyhook controller. The adaptive control outperforms the passive-on control and passive-off control, and there are no super-harmonics in the seat acceleration measured from the MRF suspension system. Yu et al. [165-167] designed adaptive fuzzy controller through adding three elements: performance estimator, emendation and rules update to the conventional fuzzy controller. It has been demonstrated form road test that the value of the acceleration of the driver seat under the adaptive fuzzy controller declines $20.2 \%$ at most with respect to the one under passive suspension. The adaptive fuzzy controller has been also compared with the skyhook controller, and both simulation and road testing results showed that the adaptive fuzzy controller could achieve better vertical 
vibration control effects than the skyhook controller, especially in the human sensitive frequency band (4 to 8 Hertz). Yu et al. [168] also designed an adaptive fuzzy neural network controller to improve ride comfort and stability of vehicles. The fuzzy rules and membership functions of the fuzzy neural network controller have been selected by the fuzzy associated memory neural network from training data [188], which is generated by genetic algorithm [189]. With the road input and damping force for the four MRF dampers being supplied, the full-car model calculates the motion of the suspension and vehicle. Then, the genetic algorithm searches out the best damping force of the MRF damper that minimizes the fitness function in every sampling period. It has been shown from both computer simulation and road test that the pitch motion, roll motion, and vertical motion are significantly reduced by activating the proposed control strategy and hence the ride comfort and stability of vehicles is achieved.

\subsection{Other Applications}

Liao's group [141-144] designed a direct adaptive controller for a MR brake to achieve desired torque, which could assist elderly people with mobility problems. The stability of gradient update law was proved by Lyapunov theory. Experimental results showed that the MR brake had good torque tracking ability under adaptive control. Zhou and Qu [145] proposed a model-free learning adaptive semi-active control algorithm for structural vibration control. Numerical simulation was taken and the displacement of the base could be reduced by about $40 \%$ when subjected to E1 Centro earthquake. Jimenez and Alvarez-Icaza $[152,153]$ used a linear matrix inequality approach to design an adaptive observer, which identified the LuGre model parameters and structure stories positions and velocities based on acceleration and force measurements. The vibration controller was developed with Lyapunov theory and verified in a numerical simulation that the E1 Centro earthquake was applied to a three-story building. When compared with the uncontrolled one, the displacement, velocity and acceleration of the building declined $86.95 \%, 86.95 \%$ and $51.13 \%$ at most, respectively. Shirazi et al. [154] used the estimator in [147,148] to identify Bouc-Wen model parameters and a $H \infty$ controller to compute the required damping force to attenuate the system vibration. The controller design methodology in self-tuning regulator is flexible, and different kinds of composite controllers such as adaptive fuzzy controller [155-172], adaptive sliding mode controller [173-176] and adaptive neural network controller [177-183] have been adopted in semi-active MRF damper systems. Yang et al. [155] simulated adaptive fuzzy algorithm to the semi-active suspension system with MRF damper. The results showed that the improvement of suspension performance under adaptive fuzzy controller with respect to the one under conventional fuzzy controller is $30.28 \%$ at most and the controller had good self-adaptability to different working conditions. Zhou et al. [156-159] proposed adaptive fuzzy controller to protect buildings with MRF dampers against dynamic hazards, and the controller achieved satisfactory control effect in simulations. Wang et al. $[160,161]$ designed MRF gun recoil damper, and three control strategies, including ON-OFF control method, PID control method and adaptive fuzzy control method, were applied to the damper to control high impact load. Experimental results showed that the adaptive fuzzy controller could achieve better effect than ON-OFF and PID control algorithm. Designing adjustment mechanism for scale factor and quantization factor of fuzzy controller is an effective way to implement adaptive fuzzy controller. Li et al. [162] designed an adaptive fuzzy controller for engine vertical vibration isolation, which could online adjust scale factor and 
quantization factor by human-simulation intelligent parameter modifying algorithm. Yang et al. [163,164] found that in the lateral semi-active suspension system of high-speed locomotive installed with MRF damper, when the lateral velocity and acceleration were great, the scale factor of input velocity and acceleration and quantization factor of output current should be decreased and increased, respectively. When the velocity and acceleration were small, the scale factor and quantization factor should be increased and decreased. Numerical simulation results suggested that the lateral acceleration under adaptive fuzzy controller decreased $47.03 \%$ and $34.40 \%$ with respect to the ones under passive suspension and under fuzzy controller, respectively. Yu et al. [165-167] added three elements (performance estimator, emendation and rules update) to the conventional fuzzy algorithm to obtain adaptive fuzzy controller. To improve ride comfort and stability of vehicles, Yu et al. [168] also designed an adaptive fuzzy neural network controller, fuzzy rules and membership functions of which were selected by fuzzy associated memory neural network from training data. Other research works on adaptive controller applied to MRF and MRE systems can be founded in [129, 146, $147,148,149,150,151,152,153,154,156,157,158,159,169,184,185,170,171,172,173,174,190]$.

\section{Neural Network Controller}

In the 1940s, McCulloch and Pitts proposed a model for biological neurons and biological neural networks (NN). However, neural networks are far too simple to serve as realistic brain models on the cell level, but they might serve as very good models for the essential information processing tasks that organisms perform. This remains an open question because we have so little understanding of how the brain actually works [232]. In a neural network, neurons are joined by directed arcs-connections. The neuron and arcs constitute the network topology. Each arc has a numerical weight that specifies the influence between two neurons. Positive weights indicate reinforcement; negative weights represent inhibition. NN plays a fundamental role in neural computation, as they have been widely applied in many different areas including pattern recognition, image processing, intelligent control, time series prediction, etc. When an input is later applied, the neural network provides an output response to indicate the class to which the input pattern belongs. In short, NN learn to approximate sampled functions even when their form cannot be specified precisely and hence NN models represent a new approach to systems engineering that is potentially robust [243]. A control scheme of a neural networks system is expressed in Figure 9. The inputs of plant are used as the inputs of neural networks model.

Components of neural networks include $p$ neurons, the weight $w$, and the bias value $\theta$. Output $y_{k}$ of the neural networks model will be used to calculate error $e(t)$ with output of the plant $y$. The error $e(t)$ is found by the desired output $d(t)$ and the output plant $y(t)$. This error is used as the input of learning algorithm which adjusts the neural networks model. Neural networks can only come into play if the problem is expressed by a sufficient amount of observed examples. These observations are used to train the black box. On the one hand no prior knowledge about the problem needs to be given. On the other hand, however, it is not straightforward to extract comprehensible rules from the neural network's structure. On the contrary, a fuzzy system demands linguistic rules instead of learning examples as prior knowledge. Furthermore the input 
and output variables have to be described linguistically. If the knowledge is incomplete, wrong or contradictory, then the fuzzy system must be tuned. Since there is not any formal approach for it, the tuning is performed in a heuristic way. This is usually very time consuming and error-prone. It is desirable for fuzzy systems to have an automatic adaption procedure which is comparable to neural networks. Combining both approaches should unite advantages and exclude disadvantages, so it has been more attractive attention in control fields [226].

\subsection{Vehicle Suspension System}

It is known that control performance of model based control scheme heavily depends on the accuracy of the dynamic model. In real field, the dynamic model of the MR suspension system is very complex and includes nonlinearities. Therefore, an intelligent controller which is less sensitive to the model accuracy may bring good control performance for the vehicle suspension system. The fuzzy neural network controller (FNNC) incorporated with the self-learn knowledge can improve stability of semi-active system. The dynamic model of the full car equipped with MRF dampers was used in [226]. With the road input and damping force for the four MRF dampers being supplied, the full-car model calculates the motion of the suspension and vehicle. Then, the genetic algorithm searches out the best damping force of the MRF damper that minimizes the fitness function in every sampling period. A series of such damping force and system state are stored as teaching signals for fuzzy associative memory neural network (FAMNN). The error of the teaching signals and FAMNN's outputs is used to adjust the knowledge base. As a feedback, the knowledge base affects the FAMNN's output until the error is small enough. Before evaluating control performance via the road test, computer simulation is undertaken. The road roughness is chosen based on ISO 8606. It has been shown from results of computer simulation that MRF damper suspension employing FNNC reduces the pitch, roll and vertical acceleration of car body compared to the passive suspension up to the second resonance frequency of $10.3 \mathrm{~Hz}$. However, it was also observed that control performance was degraded at high frequency region above the second resonance frequency. This is because the semi-active MRF dampers cannot supply enough energy to such high resonance modes. Because human body is not sensitive to the vibration beyond $12.5 \mathrm{~Hz}$, the FNNC can achieve good roll ability in weighted root mean square (WRMS) value with weighted average in frequency domain. For the comparative study on control performances of the FNNC, a traditional sky-hook control strategy of the MRF damper suspension has been also evaluated. It has been demonstrated that the proposed FNNC is better than the sky-hook controller in terms of ride comfort and vehicle stability. As a second step for control performance evaluation, the road test is undertaken. The semi-active suspension control system of a passenger car equipped with the MRF dampers was set up and road tests were conducted. In order to discuss the performance of the proposed FNNC, a conventional sky-hook controller was also

utilized in the test. It has been clearly observed that pitch motion, roll motion and vertical motion are effectively reduced by activating the proposed FNNC. In addition, it has been shown that the proposed FNNC produces better control performance than the conventional sky-hook controller.

\subsection{Other Applications}


It is generally known that $\mathrm{NN}$ is used to identify the forward and inverse mode of MRF damper in semi-active control system [214-224]. There is an example inverse mode identification of MRF Damper with NN in seat suspension system, which is illustrated in [218]. When the inverse model of MRF damper for damping controller was applied to the semi-active control system, the requirements for model accuracy and fast realtime control became more rigid. It has been shown that unwanted vibrations of the driver's seat can be substantially reduced using the proposed controller. On the other hand, in order to characterize the performance of MRF dampers associated with the neural networks, mathematical models need to be established in an accurate manner for capturing the nonlinear behavior of MRF dampers. Generally, they can be grouped as parametric and non-parametric models. Parametric models include the Bingham model [196], the viscoelastic-plastic model [197], the phenomenological model [198], the semi-phenomenological model based on the Bouc-Wen model [199], the improved Bouc-Wen model [200,201], the hyperbolic tangent function model [202-203], the inverse tangent function model [204], and many others. The Bingham and viscoelastic-plastic models cannot reproduce the nonlinear behavior of an MR damper with high accuracy, while the other models can; however, they have many parameters, the corresponding models for the inverse dynamics of the MR dampers are often difficult to obtain due to their nonlinear characteristics. In the nonparametric models, such as polynomial model [205-207], statistical models [208], nonlinear black box model [209-210], NARX model [211], fuzzy logic (FL) [212-213] and artificial neural networks (ANNs) [214-226]. Models based on lookup tables, FL and artificial neural networks (ANNs) are the most representative frameworks for MRF dampers. While fuzzy models need an a priori knowledge of the MR damper, the ANN, which can approximate any nonlinear function, has high robustness and self-learning ability and good fault tolerant performance [227], is one of the most representative non-parametric models for the MRF damper. Since an open-loop control is easy to implement and cost-effective comparing with a closed-loop control, it is valuable to develop the accurate inverse dynamic models of MRF dampers that are required in the realization of semi-active control. Due to the property of neural networks to implement input-output mappings, they are very suitable for applications on identification, control and optimization of semi-active control system. NN can be also a controller or hybrid controller combined with other control algorithms for a semi-active control system $[191,226,237]$.

\section{H-infinity Controller}

Since Zames [243] introduced the basic motivations for $H_{\infty}$ optimization, this problem has attracted considerable research interest. $H_{\infty}$ methods were initially developed in the frequency domain to synthesize controllers achieving stabilization with guaranteed performance. They offer solutions to solve mathematical optimization problems which are expressed as a transfer function of the expected output to the disturbance. The derivation of state-space solutions to $H_{\infty}$-optimal control problems was then truly a breakthrough in linear control theory [244]. Their control objectives are to minimize the $H_{\infty}$ norm of the transfer matrixes. Moreover, significant interest emerged in extending this derivation to nonlinear systems. This extension has placed the $H_{\infty}$ methods in a much wider application environment. $H_{\infty}$ techniques have the advantage over 
classical control techniques in that they can take consideration of both closed-loop system stability and system performance; especially they are readily applicable to problems involving multivariate system. They have evolved into a mature robust control theory through years' development and improvement in control theory, design practice, and application. Figure 10 states the standard configuration of an $H \infty$ controller, where $P$ is the plant, $K$ is the controller feedback, $w$ is the external disturbance, $z$ is the variable to be minimized, $y$ is the plant output, and $u$ is the control input. It should be noted that $w, z, y$, and $u$ are vectors but $P$ and $K$ are matrices. Algebraic representation of the above closed loop model is expressed as follows:

$$
\left[\begin{array}{l}
z \\
y
\end{array}\right]=P(s)\left[\begin{array}{l}
w \\
u
\end{array}\right]=\left[\begin{array}{ll}
P_{11}(s) & P_{12}(s) \\
P_{21}(s) & P_{22}(s)
\end{array}\right]\left[\begin{array}{l}
w \\
u
\end{array}\right]
$$

Then, from Figure 10 it can be interpreted that $u=y(s)$. In system showed above, the goal is minimizing the error variable $z$. Therefore, the transfer function $P$ from exogenous input $w$ to minimized output $z$ can be written as:

$z=\left\lfloor P_{11}+P_{12} K\left(I-P_{22} K\right)^{-1} P_{21}\right\rfloor w=F_{l}(P, K) w=T_{z w} w$

where $F_{l}(P, K)$ is called the lower linear fractional transformation. The objective of $H \infty$ algorithm is to find a feedback controller $K$ that minimizes the $H \infty$ norm of $F_{l}(P, K)$ or $T_{z w} w$, i.e.:

$\min \left\|T_{z w}\right\|_{\infty} \quad-H \infty$ optimal control

or $\left\|T_{z w}\right\|_{\infty}<\gamma \quad$ - sub-optimal Hळ control

In the above, $\gamma$ is the given positive real number. The infinity norm of the transfer function matrix $F_{l}(P, K)$ is defined as:

$\left\|F_{l}(P, K)\right\|_{\infty}=\sup \bar{\sigma}\left(F_{l}(P, K)(j w)\right)$

where $\bar{\sigma}$ is the maximum singular value of the matrix $F_{l}(P, K)(j w)$

\subsection{MRE Isolator}

This section gives an example studying the sup-optimal $H_{\infty}$ control of a vehicle seat suspension featuring a MRE isolator [260]. The proposed MRE seat isolator is composed of core and base, coil, nonmagnetic rings, and MRE samples. After formulating governing equations in a state space model, the following damping force of the MRE isolator was determined. In order to evaluate control performances, two kinds of road excitations, i.e., bump road disturbance and random road disturbances, were chosen to run the integrated seat suspension system. The detailed definitions for these two excitations can be referenced to [260]. It has been demonstrated that the proposed MRE isolator achieves the best performance among all the compared isolators. It was also shown that the isolator with maximum stiffness generates the worst performance on ride 
comfort in terms of the peak value of acceleration. The proposed MRE isolator under $H_{\infty}$ controller performs better for a wide range of stiffness.

\subsection{Other Applications}

The combination of the MR devices and the $H_{\infty}$ methods offers solutions to the above problem and is extensively applied to vehicle suspension including full car suspension, half car suspension, and quarter car suspension [251-255], train suspension [257, 258], seat suspension [260], bridges [248], buildings [246, 247, 249, 261], engine mount [262], and landing gear [263]. A $H_{\infty}$ controller which achieves inherent robustness against system uncertainties through treating the sprung mass of a full-vehicle suspension system featuring MR dampers as uncertain parameter was formulated in [264]. In order to approximate the desired active force from the $H_{\infty}$ controller for the actual MRF damper, inverse model is a favorable choice as it can output a desired current signal to the MR damper $[252,253] . H_{\infty}$ controller can provide a desired damping force depending on the real time response of the vehicle suspension for the inverse model of MRF damper to achieve; then the reverse model outputs an input current to the actual MRF damper so that it can offer an actual damper force to the vehicle suspension. A study on the direct voltage control of a MRF damper for application in a quarter car suspension through the design of an $H_{\infty}$ controller that considers the suspension performance requirements and the constraint on the input voltage for the MR damper was undertaken [251]. The most advancement of this study is designing a controller directly targeting system performance without judging the semi-active condition and getting rid of the dependence on the inverse model of the MRF damper. Apart from ordinary vehicle suspensions, railway vehicles are also important targeting systems that require vibration reduction. Two MRF dampers on a full-scale railway vehicle of 17-degree-of-freedom for the lateral ride quality improvement with $H_{\infty}$ control was applied in [257]. In this study, the MRF dampers are inversely modelled by the neuro-fuzzy inference system (ANFIS) and the Ho controller is composed of a yaw motion controller and a rolling pendulum controller. It has been shown that the proposed control system attenuates the lateral, yaw, and roll accelerations of the vehicle body significantly (about 30\%). MRF dampers are also used to protect the bridges and structures from the vibration damage. An $H_{\infty}$ control algorithm to drive damping forces of MRF dampers was derived in [248] to reduce the resonant response of high-speed railway bridges, and semi-active control of $\mathrm{H} \infty$ was adopted for the floor system with a new input shaping filter developed to account for the input motion characteristics and enhance the effectiveness of the controller [249]. The application of MRF damper and $H_{\infty}$ control algorithm was also extended into reducing the excessive vibrations of an landing aircraft [264]. Combined with other methods, $H_{\infty}$ control algorithm also shows satisfactory effectiveness. A $H_{\infty}$ controller based on a Takagi-Sugeno (TS) fuzzy model for a twodegrees-of-freedom one-quarter-vehicle semi-active suspension with MRF damper was presented in [265]. The advantage of having the TS system as a reference is that it enables the linear control theory to be directly applied to design the MRF damper controller. An adaptive back-stepping control with $H_{\infty}$ performance scheme has been proposed to solve the vibration problem in a base-isolated building [247]. The resulting controller reduced the structure displacements and velocities while keeping the accelerations below the level of the uncontrolled cases. The application of MRF damper on a full vehicle suspension system under $H \infty$ controller was done in [254]. A cylindrical MR damper has been firstly designed and manufactured by 
incorporating a Bingham model of a MR fluid which is commercially available. In order to obtain a favorable control performance for the vibration reduction of the MR suspension system, a robust $H_{\infty}$ controller was designed, and the whole MR suspension system were evaluated under various road conditions through the hardware in the loop simulation (HILS) methodology for the demonstration of a practical feasibility. It has been demonstrated that the vertical acceleration is reduced about $20 \%$ near the body resonance frequency (1-2 $\mathrm{Hz}$ ) and about $30 \%$ at the wheel resonance $(10 \mathrm{~Hz})$. The PSD for the tire deflection is reduced $40 \%$ in the neighborhood of body resonance by activating MRF dampers associated with $H_{\infty}$ controller.

\section{Hybrid Controller}

Hybrid control systems are control systems that involve two or more than two conventional control strategies, such as adaptive fuzzy logic control, skyhook control, ground-hook control and etc. [267-270]. By collaboration of different strategies, the system performance can be greatly improved. The overall motivation for hybrid methods is significant interaction between the multiple targets to optimize. Furthermore, hybrid technique is the need for hierarchical organization of controls in many of today's complex technical systems. Three major criteria are usually applied to assessment of overall performances of semi-active suspensions control, including road handling, ride comfort, and stability. It is widely known that most of strategies or control algorithms can only achieve better performance in one or two criteria. This character limits the improvement of the vehicle overall performances. Thus, it is crucial to develop advanced control strategies to well improve overall performances of semi-active suspensions. This is the major motivation of hybrid control. An example of hybrid control of fuzzy control and neural network control is expressed in Figure 11. As an example of the hybrid controller, consider a controller integrating the skyhook controller and ground-hook controller given by

$$
\begin{gathered}
F_{\text {sky }}= \begin{cases}G_{\text {sky }} \dot{x}_{2} & \dot{x}_{2}\left(\dot{x}_{2}-\dot{x}_{1}\right)>0 \\
0 & \dot{x}_{2}\left(\dot{x}_{2}-\dot{x}_{1}\right) \leq 0\end{cases} \\
F_{\text {ground }}= \begin{cases}-G_{\text {ground }} \dot{x}_{1} & \dot{x}_{1}\left(\dot{x}_{2}-\dot{x}_{1}\right)<0 \\
0 & \dot{x}_{1}\left(\dot{x}_{2}-\dot{x}_{1}\right) \geq 0\end{cases}
\end{gathered}
$$

where $\dot{x}_{2}$ is absolute velocity of the sprung mass/car body, $\dot{x}_{1}$ is absolute velocity of the unsprung mass, $\dot{x}_{2}-$ $\dot{x}_{1}$ is the velocity of the sprung mass relative to the unsprung mass, $F_{s k y}$ is the skyhook damping force, $G_{s k y}$ is the skyhook gain, $F_{\text {ground }}$ is the groundhook damping force, and $G_{\text {ground }}$ is the ground-hook gain. The control law of the hybrid strategy can be defined as:

$$
F_{\text {hybrid }}=\eta F_{\text {sky }}+(1-\eta) F_{\text {ground }}
$$

where $\eta \epsilon(0,1)$ is the tunable hybrid weighting factor that balances the effect of the skyhook controller and the ground-hook controller to improve both ride comfort and handling stability. 
For the MRF suspension system, a variety of intelligent control strategies such as fuzzy logical control, adaptive control and neural network control were worked together to complete control task more efficiently. For example, a neural network based fuzzy control approach was proposed in $[271,272,273]$ to improve ride comfort and road handling of heavy vehicles using semi-active dampers via numerical simulation without involving in modeling and inverse modeling of MRF damper. With considering the coupling of four wheels and vehicle stability, Yu et al. [269] introduced fuzzy neural network control utilizing a dynamic model of a full car equipped with MRF dampers. To develop a fuzzy logic control system, a hybrid control system combining the powerful searching capability of genetic algorithms (GA) in the design of a fuzzy controller has been also proposed in [274]. GA is a powerful multi-objective optimization method to pursue the goal of simultaneously reducing both the displacement response and the acceleration response, which determine the safety and comfort level criteria respectively. A few controllers [269, 270, 275] integrated fuzzy and neural network incorporated with the self-learn knowledge are great hybrid control system to enhance vehicle stability. Neural-network (NN)-based control techniques is also a concerned hybrid control [275-281]. Rashid [282] developed a hybrid fuzzy logic plus proportional-integral-derivative (PID) controller for analysis of a similar quarter-car model. SMC is one of best candidates to formulate a certain hybrid controller due to its inherent robustness against disturbances and uncertainties [283, 284]. In [285], a hybrid control system integrating a skyhook surface sliding model control (skyhook SMC) was designed and simulated. It has been shown that the proposed hybrid controller provides much better ride comfort of a semi-active vehicle suspension than each controller only. Furthermore, A hybrid control including skyhook and ground-hook control was also developed to improve both ride quality and road holding ability by the LQR control using a minimum norm criterion [270]. The fuzzy controller was designed upon on the skyhook and ground-hook theory in [288]. To build the fuzzy-skyhook controller, the velocity of car body sprung mass and the relative velocity between sprung mass and un-sprung mass act as the inputs of the controller. The output was designed to be the desired fuzzy-skyhook force. Similarly, the inputs of the fuzzy-ground-hook controller were the velocity of un-sprung mass (wheel) and the relative velocity between the sprung mass and un-sprung mass, while the output was the desired fuzzy-ground force. The universe of discourse of the input and output variables was selected based on the results of the simulation under different conditions. It was determined based on the amplitude of the open-loop responses within the minimum and maximum ranges of the signal. An adaptive fuzzy-hybrid (AF-H) controller was introduced in [289] and applied to the vehicle suspension. It has been shown that the proposed hybrid controller can reduce the imposed displacement more than $65 \%$ compared with the passive system. An intelligent hybrid controller which is less sensitive to the model accuracy may bring good control performance for the vehicle suspension system [269]. In this example, a model-free neural network control algorithm was employed to design a controller for achieving roll control [290, 291]. With the road input and damping force of MRF dampers being supplied, the full-car model calculates the motion of the suspension and vehicle. Then, the GA searches out the best damping force of the MR damper that minimizes the fitness function in every sampling period. In order to demonstrate some advantages of the hybrid controller, a random road test based on ISO 8606 was imposed. It has been shown that the employed hybrid controller can remarkably reduce pitch, roll and vertical acceleration of car body the frequency up to $10.3 \mathrm{~Hz}$. 


\section{Concluding Remarks}

As review in this article, numerous control strategies for many different application systems using MRF and MRE have been developed and some of control schemes have been successfully realized for commercial products featuring MRF and MRE. It has been identified from this review article that in addition to efforts to develop more advanced MRF and MRE materials which exhibit higher yield stress, lower sedimentation and wider operating temperature, an appropriate design of controller is also a crucial factor to aid commercial development of advanced MRF and MRE application devices and systems. Several specifications in the process of controller design such as output response time, robust stability and control accuracy need to be specially considered. It has been described in this article that each controller has its own inherent advantages and disadvantages. Therefore, in order to achieve control performance targets of MRF and MRE application systems, the use of single controller and the use of hybrid controller consisting of more than two different controllers should be carefully treated. Moreover, the cost effectiveness of controller implementation to real products is also a significant factor to be considered. Table 2 summarizes many different controllers applied to many different MRF and MRE application systems. It is finally remarked that this review article on control schemes can accelerate the realization of commercial products of MRF and MRE application systems and provide a great help to create more advanced control schemes which can be optimally fitted to practical application systems. 


\section{References}

1. Seung-Bok Choi, Moo-Ho Nam, Byung-Kyu Lee 2000 Vibration control of a MR seat damper for commercial vehicles Journal of Intelligent Material Systems and Structures 11 936-944

2. Y. M. Han, M. H. Nam, S. S. Han, H. G. Lee, S. B. Choi 2002 Vibration control evaluation of a commercial vehicle featuring MR seat damper Journal of Intelligent Material Systems and Structures 13 575-579

3. G.Z. Yao, F.F. Yap, G. Chen, W.H. Li, S.H. Yeo 2002 MR damper and its application for semiactive control of vehicle suspension system Mechatronics 12 963-973

4. W H Liao, C Y Lai 2002 Harmonic analysis of a magnetorheological damper for vibration control Smart Materials and Structures $11288-296$

5. Mehdi Ahmadian, Xubin Song, Steve C. Southward 2004 No-jerk skyhook control methods for semiactive suspensions Journal of Vibration And Acoustics 126 580-584

6. Shuqi Guo, Shaohua Li, Shaopu Yang 2006 Semi-active vehicle suspension systems with magnetorheological dampers IEEE International Conference on Vehicular Electronics and Safety 403-406

7. Jeongmok Cho, Hyoun Young Kim, Taegeun Jung, Joongseon Joh 2007 Fuzzy control of shearmode mr damper under impact force Smart Structures, Devices, and Systems III, Proc. of SPIE 6414641400

8. D. Y. Lee, Y. J. Nam, R. Yamane, M. K. Park 2009 Performance evaluation on vibration control of $\mathrm{mr}$ landing gear 11th Conference on Electrorheological Fluids and Magnetorheological Suspensions Journal of Physics: Conference Series 149012068

9. Xiao-min Dong, Miao Yu, Chang-rong Liao, Wei-min Chen 2010 Comparative research on semiactive control strategies for magneto-rheological suspension Nonlinear Dynamics 59 433-453

10. X. Song and M. Ahmadian 2010 Characterization of semi-active control system dynamics with magneto-rheological suspensions Journal of Vibration and Control 16 1439-1463

11. H. J. Yao, J. Fu, M. Yu, Y. X. Peng 2013 Semi-active Ho control of seat suspension with MR damper 13th Int. Conf. on Electrorheological Fluids and Magnetorheological Suspensions (ERMR2012) Journal of Physics: Conference Series 412012054

12. Moon K. Kwak, Jae-Ha Lee, Dong-Ho Yang, Won-Hee You 2014 Hardware in-the-loop simulation experiment for semi-active vibration control of lateral vibrations of railway vehicle by magneto-rheological fluid damper Vehicle System Dynamics: International Journal of Vehicle Mechanics and Mobility 52:7 891-908

13. Wei Zhu, Xiao-ting Rui 2014 Semiactive vibration control using a magnetorheological damper and a magnetorheological elastomer based on the Bouc-Wen model Shock and Vibration ID 405421

14. Mehdi Ahmadian and Christopher A. Pare 2000 A quarter-car experimental analysis of alternative semiactive control methods Journal of Intelligent Material Systems and Structures 11 604-612 
15. Sergio M. Savaresi, Cristiano Spelta 2007 Mixed sky-hook and approaching the filtering limits of a semi-active suspension Journal of Dynamic Systems, Measurement, and Control 129 382-392

16. Min Sang Seong, Seung Bok Choi, Cheol Ho Kim 2011 Design and performance evaluation of MR damper for integrated isolation mount Journal of Intelligent Material Systems and Structures 22 1729-1738

17. Mehdi Ahmadian, Emmanuel Blanchard 2011 Non-dimensionalised closed-form parametric analysis of semi-active vehicle suspension using a quarter-car model Vehicle System Dynamics: International Journal of Vehicle Mechanics and Mobility 49:1 219-235

18. Karl J. Astrom, Bjorn Wittenmark 2008 Adaptive control, second edition Dover publications, INC. Mineola, New York

19. Hwan-Soo Lee, Seung-Bok Choi 2000 Control and response characteristics of a magnetorheological fluid damper for passenger vehicles Journal of Intelligent Material Systems and Structures 11 80-87

20. Feng Tyan $2008 \mathrm{H}$ infinity-PD controller for suspension systems with MR dampers Proceedings of the 47th IEEE Conference on Decision and Control 4408-4413

21. Banna Kasemi, Asan G. A. Muthalif, M. Mahbubur Rashid, Sharmila Fathima 2012 Fuzzy-PID controller for semi-active vibration control using magnetorheological fluid damper Procedia Engineering 411221 - 1227

22. Ozan Erol, Berk Gonenc, Doruk Senkal, Sait Alkan, Hakan Gurocak 2012 Magnetic induction control with embedded sensor for elimination of hysteresis in magnetorheological brakes Journal of Intelligent Material Systems and Structures 23 427-440

23. Constantin Ciocanel, Mohammad H. Elahinia, Kevin E. Molyet, Nagi G. Naganathan 2008 Design analysis and control of a magnetorheological fluid based torque transfer device International Journal of Fluid Power 9:319-24

24. Jong-Seok Oh, Seung-Hyun Choi, Seung-Bok Choi 2014 Design of a 4-DOF MR haptic master for application to robot surgery: virtual environment work Smart Materials and Structures $\mathbf{2 3}$ 095032

25. Brian D. O. Anderson, John B. Moore 1989 Optimal control linear quadratic methods Prentice Hall international, Inc. Englewood Cliffs NJ 07632

26. W. Fred Ramirez 1994 Process control and identification Academic press, Inc. 1250 Sixth avenue San Diego CA 92101-4311

27. S J Dyke, B F Spencer Jr, M K Sain, J D Carlson 1996 Modeling and control of magnetorheological dampers for seismic response reduction Smart Materials and Structures 5 $565-575$

28. Chih-Chen Chang, Li Zhou 2002 Neural network emulation of inverse dynamics for a magnetorheological damper Journal of Structural Engineering 128(2) 231-239

29. Hyun-Ung Oh, Junjiro Onoda 2002 An experimental study of a semiactive magneto-rheological fluid variable damper for vibration suppression of truss structures Smart Materials and Structures 11 156-162 
30. Hyun-Ung Oh 2004 Experimental demonstration of an improved magneto-rheological fluid damper for suppression of vibration of a space flexible structure Smart Materials and Structures 13 1238-1244

31. Y. F. Duan, Y. Q. Ni, J. M. Ko 2005 State-derivative feedback control of cable vibration using semiactive magnetorheological dampers Computer-Aided Civil and Infrastructure Engineering 20 431-449

32. Sung-Ryong Hong, Seung-Bok Choi 2005 Vibration control of a structural system using magnetorheological fluid mount Journal of Intelligent Material Systems and Structures 16 931-936

33. Chun-Wei Zhang, Jin-Ping Ou, Jin-Qiu Zhang 2006 Parameter optimization and analysis of a vehicle suspension system controlled by magnetorheological fluid dampers Structural Control Health Monitoring 13 885-896

34. H.H. Tsang, R.K.L. Su, A.M. Chandler 2006 Simplified inverse dynamics models for MR fluid dampers Engineering Structures 28 327-341

35. Mansour A. Karkoub, Mohamed Zribi 2006 Active/semi-active suspension control using magnetorheological actuators International Journal of Systems Science 37:1 35-44

36. Hui Li, Min Liu, Jinhai Li, Xinchun Guan, Jinping Ou 2007 Vibration control of stay cables of the shandong binzhou yellow river highway bridge using magnetorheological fluid dampers Journal of Bridge Engineering 12(4) 401-409

37. Seung-Bok Choi, Sung-Ryong Hong, Kum-Gil Sung, Jung-Woo Sohn 2008 Optimal control of structural vibrations using a mixed-mode magnetorheological fluid mount International Journal of Mechanical Sciences 50 559-568

38. Zhi Q. Gu, S. Olutunde Oyadiji 2008 Application of MR damper in structural control using ANFIS method Computers and Structures 86 427-436

39. Yeesock Kim, Reza Langari, Stefan Hurlebaus 2009 Semiactive nonlinear control of a building with a magnetorheological damper system Mechanical Systems and Signal Processing 23 300315

40. Vasudevan Rajamohan, Ramin Sedaghati, Subhash Rakheja 2011 Optimal vibration control of beams with total and partial MR fluid treatments Smart Materials and. Structures 20115016

41. Seiyed Hamid Zareh, Atabak Sarrafan, Amir Ali Akbar Khayyat, Abolghassem Zabihollah 2012 Intelligent semi-active vibration control of eleven degrees of freedom suspension system using magnetorheological dampers Journal of Mechanical Science and Technology 26(2) 323-334

42. Daniel A Pohoryles, Philippe Duffour 2013 Adaptive control of structures under dynamic excitation using magnetorheological dampers: an improved clipped-optimal control algorithm Journal of Vibration and Control (published online) doi:10.1177/1077546313510543

43. Irfan H. Vadtala, Devesh P. Soni, Dolarray. G. Panchal 2013 Semi-active control of a benchmark building using neuro-inverse dynamics of MR damper Procedia Engineering 5145 - 54

44. D. H. Wang, W. H. Liao 2009 Semi-active suspension systems for railway vehicles using magnetorheological dampers. Part I: system integration and modelling Vehicle System Dynamics: International Journal of Vehicle Mechanics and Mobility 47:11 1305-1325 
45. D. H. Wang, W. H. Liao 2009 Semi-active suspension systems for railway vehicles using magnetorheological dampers. Part II: simulation and analysis Vehicle System Dynamics: International Journal of Vehicle Mechanics and Mobility 47:12 1439-1471

46. W. H. Liao, D. H. Wang 2003 Semiactive vibration control of train suspension systems via magnetorheological dampers Journal of Intelligent Material Systems and Structures 14 161-172

47. Miao Yu, X. M. Dong, S. B. Choi, C. R. Liao 2009 Human simulated intelligent control of vehicle suspension system with MR dampers Journal of Sound and Vibration 319 753-767

48. Jean Jacques E. Slotine, Weiping Li 1991 Applied nonlinear control Prentice-Hall international, Inc. Englewood Cliffs NJ 07632

49. Makoto Yokoyama, J. Karl Hedrick, Shigehiro Toyama 2001 A model following sliding mode controller for semi-active suspension systems with $\mathrm{mr}$ dampers Proceedings of the American Control Conference 2652-2657

50. R. K. Dixit, G. D. Buckner 2005 Sliding mode observation and control for semiactive vehicle suspensions Vehicle System Dynamics: International Journal of Vehicle Mechanics and Mobility 43:2 83-105

51. Edward J. Park, Dilian Stoikov, Luis Falcao da Luz, Afzal Suleman 2006 A performance evaluation of an automotive magnetorheological brake design with a sliding mode controller Mechatronics 16 405-416

52. L. Zheng, Y. N. Li, J. Shao, X. S. Sun 2007 The design of a fuzzy-sliding mode controller of semi-active suspension systems with MR dampers Fourth International Conference on Fuzzy Systems and Knowledge Discovery (FSKD 2007) 4 514-518

53. Vijay A. Neelakantan, Gregory N. Washington 2008 Vibration control of structural systems using $\mathrm{mr}$ dampers and a 'modified' sliding mode control technique Journal of Intelligent Material Systems and Structures 19 211-224

54. Xiaomin Dong, Miao Yu, Zhi Guan 2011 Adaptive sliding mode fault-tolerant control for semiactive suspension using magnetorheological dampers Journal of Intelligent Material Systems and Structures 22 1653-1660

55. Jia-ling Yao, Wen-ku Shi, Jia-qiang Zheng, Hong-ping Zhou 2013 Development of a sliding mode controller for semi-active vehicle suspensions Journal of Vibration and Control 19 1152-1160

56. L. Y. Li, G. Song, J. P. Ou 2008 Observer and controller design for vibration suppression of a structure with MR brakes as nonlinear hinges Earth and Space 1-10 doi: 10.1061/40988(323)203

57. Q. P. Ha, M. T. Nguyen, J. Li, N. M. Kwok 2013 Smart structures with current-driven MR dampers: modeling and second-order sliding mode control IEEE/ASME Transactions on Mechatronics 186 1702-1712

58. Masoud Hemmatian, Abdolreza Ohadi 2013 Sliding mode control of flexible rotor based on estimated model of magnetorheological squeeze film damper Journal of Vibration and Acoustics 135 051023-1-051023-11

59. Do Xuan Phu, Nguyen Vien Quoc, Joon-Hee Park, Seung-Bok Choi 2014 Design of a novel adaptive fuzzy sliding mode controller and application for vibration control of magnetorheological 
mount Proceedings of the Institution of Mechanical Engineers, Part C: Journal of Mechanical Engineering Science 228 2285-2302

60. J. S. Oh, W. K. Shin, C. H. Uhm, S. R. Lee, Y. M. Han, S. B. Choi 2013 Control of haptic master - slave robot system for minimally invasive surgery (MIS) 13th Int. Conf. on Electrorheological Fluids and Magnetorheological Suspensions (ERMR2012) Journal of Physics: Conference Series 412012041

61. Hee Dong Chae, Seung- Bok Choi 2015 A new vibration isolation bed stage with magnetorheological dampers for ambulance vehicles Smart Materials and Structures 24017001

62. Shao Bo Lu, Yi Nong Li, Seung Bok Choi, Ling Zheng, Min Sang Seong 2011 Integrated control on MR vehicle suspension system associated with braking and steering control Vehicle System Dynamics: International Journal of Vehicle Mechanics and Mobility 49:1-2 361-380

63. Du H., Yim Sze K., Lam J. 2005 Semi-active $H_{\infty}$ control of vehicle suspension with magnetorheological dampers Journal of Sound and Vibration 283(3) 981-996

64. Choi S. B., Lee H. S., Park Y. P. $2002 H_{\infty}$ control performance of a full-vehicle suspension featuring magnetorheological dampers Vehicle System Dynamics 38(5) 341-360

65. Hyun-Chul Sohn, Kyung-Tae Hong, Keum-Shik Hong, Wan-Suk Yoo 2004 An adaptive LQG control for semi-active suspension systems International Journal of Vehicle Design 34(4) 309-326

66. Wang D. H., Liao W. H. 2009 Semi-active suspension systems for railway vehicles using magnetorheological dampers. Part I: system integration and modelling Vehicle System Dynamics 47(11) $1305-1325$

67. Rodriguez-Canales J., Hanson J. C., Hipp J. D., et al. 2013 Optimal molecular profiling of tissue and tissue components: defining the best processing and micro dissection methods for biomedical applications Pancreatic Cancer 980 61-120

68. Ying Z. G., Ni Y. Q., Ko J. M. 2005 Semi-active optimal control of linearized systems with multidegree of freedom and application Journal of Sound and Vibration 279(1) 373-388

69. Dyke S. J., Spencer Jr. B. F., Sain M. K., et al. 1996 Modeling and control of magnetorheological dampers for seismic response reduction Smart Materials and Structures 5(5) 565

70. Yokoyama M., Hedrick J. K., Toyama S. 2001 A model following sliding mode controller for semi-active suspension systems with MR dampers American Control Conference Proceedings of the 2001. IEEE 4 2652-2657

71. Chen B. C., Shiu Y. H., Hsieh F. C. Sliding-mode control for semi-active suspension with actuator dynamics Vehicle System Dynamics 49(1-2) 277-290

72. Guo D. L., Hu H. Y., Yi J. Q. 2004 Neural network control for a semi-active vehicle suspension with a magnetorheological damper Journal of Vibration and Control 10(3): 461-471

73. Al-Holou N., Joo D. S., Shaout A. 1994 The development of fuzzy logic based controller for semiactive suspension system Circuits and Systems, Proceedings of the 37th Midwest Symposium on. IEEE 2 1373-1376 
74. Nicolas C F, Landaluze J, Castrillo E, et al. 1997 Application of fuzzy logic control to the design of semi-active suspension systems Fuzzy Systems, Proceedings of the Sixth IEEE International Conference on. IEEE 2 987-993

75. Deng Z., Gao F., Liu X. 2006 Fuzzy control on semi-active suspension based on MR damper Sixth International Symposium on Instrumentation and Control Technology: Sensors, Automatic Measurement, Control, and Computer Simulation. International Society for Optics and Photonics 63584S-63584S-10

76. Wereley N. M., Pang L., Kamath G. M. 1998 Idealized hysteresis modeling of electrorheological and magnetorheological dampers Journal of Intelligent Material Systems and Structures 9(8) 642649

77. Cho S. W., Jung H. J., Lee I. W. 2005 Smart passive system based on magnetorheological damper Smart Materials and Structures 14(4) 707

78. Muhammad A., Yao X., Deng Z. Review of magnetorheological (MR) fluids and its applications in vibration control Journal of Marine Science and Application 5(3) 17-29

79. Battaini M., Casciati F., Faravelli L. 1998 Fuzzy control of structural vibration. An active mass system driven by a fuzzy controller Earthquake Engineering and Structural Dynamics 27(11) 1267-1276

80. Symans M. D., Kelly S. W. 1999 Fuzzy logic control of bridge structures using intelligent semiactive seismic isolation systems Earthquake Engineering \& Structural Dynamics 28(1) 37-60

81. Schurter K. C., Roschke P. N. 2001 Neuro-fuzzy control of structures using magnetorheological dampers American Control Conference, Proceedings of the IEEE 2 1097-1102

82. Liu Y., Gordaninejad F., Evrensel C. A., et al. 2002 Variable-structure-system-based logic fuzzy control of bridge vibration using fail-safe magnetorheological fluid dampers SPIE's 9th Annual International Symposium on Smart Structures and Materials. International Society for Optics and Photonics 219-227

83. Klir G.J. 2000 Fuzzy sets: an overview of fundamentals, applications and personal views, ed. A.I.F.M. Engineering. Beijing Normal University Press. p. 358

84. Edwards G., Kandel A., Sankar R. 2000 Fuzzy handoff algorithms for wireless communication Fuzzy Sets and Systems 110(3) 379-388

85. Zadeh L. A. 1998 Some reflections on soft computing, granular computing and their roles in the conception, design and utilization of information/intelligent systems Soft Computing 2(1) 23-25

86. Kuo R. J., Chen C. H., Hwang Y. C. 2001 An intelligent stock trading decision support system through integration of genetic algorithm based fuzzy neural network and artificial neural network Fuzzy Sets and Systems 118(1) 21-45

87. Passino K. M., Yurkovich S., Reinfrank M. 1998 Fuzzy control Reading, MA: Addison-Wesley 42 $15-21$

88. Pourzeynali S., Lavasani H. H., Modarayi A. H. 2007 Active control of high rise building structures using fuzzy logic and genetic algorithms Engineering Structures 29(3) 346-357 
89. Jing Z. 1995 Fuzzy control principle and application Beijing: Mechanical Industry Publication House

90. Cho S. W., Jung H. J., Lee I. W. 2005 Smart passive system based on magnetorheological damper Smart Materials and Structures 14(4) 707

91. Ali S. F., Ramaswamy A. 2009 Optimal fuzzy logic control for MDOF structural systems using evolutionary algorithms Engineering Applications of Artificial Intelligence 22(3) 407-419

92. Titli A., Roukieh S., Dayre E. 1993 Three control approaches for the design of car semi-active suspension (optimal control, variable structure control, fuzzy control) Decision and Control, Proceedings of the 32nd IEEE Conference on. IEEE 2962-2963

93. Yu M., Liao C. R., Chen W. M. et al. 2006 Study on MR semi-active suspension system and its road testing Journal of Intelligent Material Systems and Structures 17(8-9) 801-806

94. Dong X., Yu M., Liao C., et al. 2010 Comparative research on semi-active control strategies for magneto-rheological suspension Nonlinear Dynamics 59(3) 433-453

95. Kasemi B., Muthalif A. G. A., Rashid M. M., et al. 2012 Fuzzy-PID controller for semi-active vibration control using magnetorheological fluid damper Procedia Engineering 41 1221-1227

96. Liu Shaoqing, Yao Bin, Yuan Shanfa, Liu Yongxuan, Zhou Kongkang 2006 Fuzzy-PID switch control on semi-active suspensions with MR damper Transactions of the Chinese Society for Agricultural Machinery 12001

97. Atray V. S., Roschke P. N. 2004 Neuro-fuzzy control of railcar vibrations using semi-active dampers Computer-Aided Civil and Infrastructure Engineering 19(2) 81-92

98. Hashiyama T., Furuhashi T., Uchikawa Y. 1995 A study on finding fuzzy rules for semi-active suspension controllers with genetic algorithm Evolutionary Computation, IEEE International Conference on. IEEE 1279

99. Zhou Y. 2014 Fuzzy semi-active control and analysis of wind-induced vibration of a ship lift Materials and Structures 1-10

100.Wilson C. M. D., Abdullah M. M. 2010 Structural vibration reduction using self-tuning fuzzy control of magnetorheological dampers Bulletin of Earthquake Engineering 8(4) 1037-1054

101.Xu Z. D., Guo Y. Q. 2008 Neuro-fuzzy control strategy for earthquake-excited nonlinear magnetorheological structures Soil Dynamics and Earthquake Engineering 28(9) 717-727

102.Gu Z. Q., Oyadiji S. O. 2008 Application of MR damper in structural control using ANFIS method Computers \& Structures 86(3): 427-436

103. Yan G., Zhou L. L. 2006 Integrated fuzzy logic and genetic algorithms for multi-objective control of structures using MR dampers Journal of Sound and Vibration 296(1) 368-382

104.Bitaraf M., Ozbulut O. E., Hurlebaus S., et al. 2010 Application of semi-active control strategies for seismic protection of buildings with MR dampers Engineering Structures 32(10) 3040-3047

105.Shook D. A., Roschke P. N., Lin P. Y., et al. 2008 GA-optimized fuzzy logic control of a largescale building for seismic loads Engineering Structures 30(2) 436-449

106. Yoshioka H., Ramallo J. C., Spencer Jr. B. F. 2002 "Smart" base isolation strategies employing magnetorheological dampers Journal of Engineering Mechanics 128(5) 540-551 
107.Jung H. J., Choi K. M., Spencer B. F., et al. 2006 Application of some semi-active control algorithms to a smart base-isolated building employing MR dampers Structural Control and Health Monitoring 13(2-3) 693-704

108.Lin P. Y., Roschke P. N., Loh C. H. 2007 Hybrid base-isolation with magnetorheological damper and fuzzy control Structural Control and Health Monitoring 14(3) 384-405

109.Kim H. S., Roschke P. N., Lin P. Y., et al. 2006 Neuro-fuzzy model of hybrid semi-active base isolation system with FPS bearings and an MR damper Engineering Structures 28(7) 947-958

110.Kim H. S., Roschke P. N. 2006 Design of fuzzy logic controller for smart base isolation system using genetic algorithm Engineering Structures 28(1) 84-96

111.Kim H. S., Roschke P. N. 2006 Fuzzy control of base-isolation system using multi-objective genetic algorithm Computer-Aided Civil and Infrastructure Engineering 21(6) 436-449

112.Jansen L. M., Dyke S. J. 2000 Semiactive control strategies for MR dampers: comparative study Journal of Engineering Mechanics 126(8) 795-803

113.Cho S. W., Kim B. W., Jung H. J., et al. 2005 Implementation of modal control for seismically excited structures using magnetorheological dampers Journal of Engineering Mechanics 131(2) $177-184$

114.Yang M. G., Chen Z. Q., Hua X. G. 2011 An experimental study on using MR damper to mitigate longitudinal seismic response of a suspension bridge Soil Dynamics and Earthquake Engineering 31(8) 1171-1181

115.Dyke S. J., Spencer Jr. B. F., Sain M. K., et al. 1996 Modeling and control of magnetorheological dampers for seismic response reduction Smart Materials and Structures 5(5) 565

116.Dyke S. J., Spencer Jr. B. F., Sain M. K., et al. 1998 An experimental study of MR dampers for seismic protection Smart Materials and Structures 7(5) 693

117.Lee H S, Choi S B. 2000 Control and response characteristics of a magneto-rheological fluid damper for passenger vehicles Journal of Intelligent Material Systems and Structures 11(1): 80-87

118. Choi S B, Nam M H, Lee B K. 2000 Vibration control of a MR seat damper for commercial vehicles Journal of Intelligent Material Systems and Structures 11(12) 936-944

119.Choi Y T, Wereley N M, Jeon Y S. 2005 Semi-active vibration isolation using magnetorheological isolators Journal of Aircraft 42(5) 1244-12

120. Yu M, Liao C R, Chen W M, et al. 2006 Study on MR semi-active suspension system and its road testing Journal of Intelligent Material Systems and Structures 17(8-9) 801-806

121.Yan G, Zhou L L. 2006 Integrated fuzzy logic and genetic algorithms for multi-objective control of structures using MR dampers Journal of Sound and Vibration 296(1) 368-382

122.Yu M, Liao C R, Li R, et al. 2006 Wavelet-based fuzzy control algorithm for magnetorheological 
suspension Journal of Functional Materials 37(5) 786-789

123.Fu J, Yao H, Yu M, et al. 2013 An experimental model identification of magneto-rheological damper with neural network and its application in seat suspension system Control Conference, 32nd Chinese. IEEE 8769-8774

124.Liu J, Xia K, Zhu C. 2009 Online prediction and intelligent control for structural vibration based on neural networks Computational Intelligence and Industrial Applications, Asia-Pacific Conference on. IEEE 1 369-372

125.Wei W, Pin-Qi X. 2011 Property adjusting of magneto-rheological damper using neural network adaptive filter Management and Service Science, International Conference on. IEEE 1-4

126.Du H, Lam J, Sze K Y. 2004 Non-fragile Hळ vibration control for uncertain structural systems Journal of Sound and Vibration 273(4) 1031-1045

127.Fallah A Y, Taghikhany T. 2014 Robust semi-active control for uncertain structures and smart dampers Smart Materials and Structures 23(9) 095040

128.Wang S G, Yeh H Y, Roschke P N. 2001 Robust control for structural systems with parametric and unstructured uncertainties Journal of Vibration and Control 7(5) 753-772

129.Song X, Ahmadian M, Southward S, et al. 2005 An adaptive semiactive control algorithm for magnetorheological suspension systems Journal of Vibration and Acoustics 127(5) 493-502

130.Åström K J, Wittenmark B. 2013 Adaptive control Courier Dover Publications

131. Slotine J J E, Li W. 1991 Applied nonlinear control Englewood Cliffs, NJ: Prentice-Hall SIMILAR REF.48

132.Sastry S, Bodson M. 2011 Adaptive control: stability, convergence and robustness Courier Dover Publications, New York

133.Liu X H, Guan P, Liu L H. 2011 Theory and application of adaptive control Science Press

134.Zheng L, Deng Z X, Li Y N. 2005 Model reference adaptive control of semi-active suspensions China Journal of Highway and Transport 18(2): 99-102

135.Bitaraf M, Barroso L R, Hurlebaus S. 2010 Adaptive control to mitigate damage impact on structural response Journal of Intelligent Material Systems and Structures 21(6) 607-619

136.Bitaraf M, Hurlebaus S. 2013 Semi-active adaptive control of seismically excited 20-story nonlinear building Engineering Structures 56 2107-2118

137.Bitaraf M, Hurlebaus S, Barroso L R. 2012 Active and Semi-active Adaptive Control for Undamaged and Damaged Building Structures Under Seismic Load Computer-Aided Civil and 
Infrastructure Engineering 27(1) 48-64

138. Bitaraf M, Ozbulut O E, Hurlebaus S, et al. 2010 Application of semi-active control strategies for seismic protection of buildings with MR dampers Engineering Structures 32(10) 3040-3047

139.Russo R, Terzo M. 2011 Design of an adaptive control for a magnetorheological fluid brake with model parameters depending on temperature and speed Smart Materials and Structures 20(11) 115003

140.Han Z J. Adaptive control 1995 Tsinghua University Press

141.Chen J Z, Liao W H. 2010 Design, testing and control of a magnetorheological actuator for assistive knee braces Smart Materials and Structures 19(3): 035029

142.Chen J, Liao W H. 2008 Development and testing of a magnetorheological actuator for an assistive knee brace The $15^{\text {th }}$ International Symposium on: Smart Structures and Materials \& Nondestructive Evaluation and Health Monitoring. International Society for Optics and Photonics 69281G-69281G-12

143.Chen J, Liao W H. 2007 Design and control of a magnetorheological actuator for leg exoskeleton IEEE International Conference on Robotics and Biomimetics 1388-1393

144.Guo H T, Liao W H. 2010 Design and control of multifunctional magnetorheological actuators for assistive knee braces SPIE Smart Structures and Materials+ Nondestructive Evaluation and Health Monitoring. International Society for Optics and Photonics 764310-764310-11

145.Zhou Q, Qu W L. 2004 Model-free learning adaptive semi-active control of structure with MR dampers Journal of Earthquake Engineering and Engineering Vibration 24(4): 127-132

146.Song X, Ahmadian M, Southward S. 2007 Analysis and strategy for superharmonics with semiactive suspension control systems Journal of Dynamic Systems, Measurement, and Control 129(6) 795-803

147.Sakai C, Ohmori H, Sano A. 2003 Modeling of MR damper with hysteresis for adaptive vibration control Decision and Control, Proceedings. $42^{\text {nd }}$ IEEE Conference on. IEEE 4 3840-3845

148.Terasawa T, Sakai C, Ohmori H, et al. 2004 Adaptive identification of MR damper for vibration control Decision and Control, $43^{\text {rd }}$ IEEE Conference on. IEEE 3 2297-2303

149.Cetin S, Zergeroglu E, Sivrioglu S, et al. 2009 Adaptive control of structures with MR damper Control Applications, (CCA) \& Intelligent Control, (ISIC), 2009 IEEE 60-65

150. Yildiz A S, Sivrioglu S, Zergeroglu E, et al. 2013 Adaptive control of semiactive quarter car model with MR damper Control Conference (ASCC), $20139^{\text {th }}$ Asian. IEEE 1-6 
151.Yıldız A S, Sivrioğlu S, Zergeroğlu E, et al. 2014 Nonlinear adaptive control of semi-active MR damper suspension with uncertainties in model parameters Nonlinear Dynamics 1-14

152.Jiménez R, Alvarez-Icaza L. 2004 Civil structures semi-active control with limited measurements American Control Conference, Proceedings of the IEEE 6 5467-5471

153.Alvarez L, Jimenez R. 2003 Semi-active control of civil structures using magnetorheological dampers American Control Conference, Proceedings of the IEEE 2 1428-1433

154.Shirazi F A, Mohammadpour J, Grigoriadis K M. 2010 An integrated approach for parameter identification and semi-active control of MR dampers American Control Conference (ACC), IEEE, 720-725

155.Yang J W, Li M, Sun S G. 2010 Adaptive dual fuzzy control method for automotive semi-active suspension with magnetorheological damper Journal of Vibration and Shock 29(8) 46-51

156.Zhou L, Chang C C, Wang L X. 2003 Adaptive fuzzy control for nonlinear buildingmagnetorheological damper system Journal of Structural Engineering 129(7) 905-913.

157.Zhou L, Chang C C. 2003 Multivariable adaptive fuzzy control for nonlinear building-MR damper systems Smart Structures and Materials. International Society for Optics and Photonics 236-246

158.Zhou L, Chang C C. 2000 Adaptive fuzzy control for a structure-MR damper system SPIE's $7^{\text {th }}$ Annual International Symposium on Smart Structures and Materials. International Society for Optics and Photonics 105-115

159.Zhou L, Chang C C, Spencer B F. 2002 Intelligent technology-based control of motion and vibration using MR dampers Earthquake Engineering and Engineering Vibration 1(1) 100-110

160.Hongsheng H, Jiong W, Suxiang Q, et al. 2009 Investigation on controllability of a Magnetorheological gun recoil damper Information and Automation, International Conference on. IEEE 1044-1049

161.Zhang L, Ma F, Wang J. 2009 Study of control system of Magnetorheological dampers under impact load Intelligent Computation Technology and Automation, Second International Conference on. IEEE $1894-897$

162.Li R, Chen W M, Li Y G. 2009 Engine isolation control via magnetorheological technology Journal of Mechanical Engineering 45(3) 183-190

163.Ma X N, Yang S P, Di S L. 2009 Semi-active lateral vibration control of a high-speed locomotive based on MR damper Journal of Vibration and Shock 28(7) 126-130

164.Zhou H T, Yang S P, Zhu H X. 2011 Fuzzy control strategy applied in lateral semi-active control of the high-speed locomotive Journal of Vibration and Shock 30(9) 145-149 
165.Dong X, Yu M, Liao C R, et al. 2006 Research on adaptive fuzzy logic control for automobile magnetorheological semiactive suspension China Journal of Highway and Transport 19(2) 111115

166.Dong X, Yu M, Liao C R, et al. 2009 Adaptive fuzzy sliding mode control for magnetorheological suspension system considering nonlinearity and time delay Journal of Vibration and Shock 28(11) $55-60$

167.Yu M, Li R, Liao C R, et al. 2005 Semi-active control for automotive front suspension based on magnetorheological damper China Mechanical Engineering 16(6) 545-549

168.Yu M, Chol S B, Dong X, et al. 2008 Fuzzy neural network control for vehicle stability utilizing magnetorheological suspension system Journal of Intelligent Material Systems and Structures 20 457-466

169.Do Xuan Phu, Shah K, Choi S B. 2014 Design of a new adaptive fuzzy controller and its implementation for the damping force control of a magnetorheological damper Smart Materials and Structures 23(6): 065012

170.Li L Y, Ou J P. 2006 Magnetorheological damper control and simulation analysis for vibration reduction of nonlinear structure based on AFSMC algorithm Journal of Earthquake Engineering and Engineering Vibration 26(2) 96-103

171.Li L Y, Song G, Ou J P. 2008 Observer and controller design for vibration suppression of a structure with MR brakes as nonlinear hinges Earth and Space Conference 2008: Proceedings of the $11^{\text {th }}$ Aerospace Division International Conference on Engineering, Science, Construction, and Operations in Challenging Environments. ASCE 1-10

172.Li L Y, Song G B, Ou J P. 2010 Experimental and theoretical analysis of intelligent control for structural nonlinear vibration Chinese Journal of Theoretical and Applied Mechanics 42(1) 115121

173. Yeh F K, Chen Y Y. 2013 Semi-active bicycle suspension fork using adaptive sliding mode control Journal of Vibration and Control 19(6) 834-846

174.Yeh F K, Huang J J, Huang C W. 2010 Adaptive-sliding mode semi-active bicycle suspension fork SICE Annual Conference, Proceedings of. IEEE 3312-3317

175.Dong X, Yu M, Guan Z. 2011 Adaptive sliding mode fault-tolerant control for semi-active suspension using magnetorheological dampers Journal of Intelligent Material Systems and Structures 22(15) 1653-1660

176.Phu D X, Quoc N V, Park J H, et al. 2014 Design of a novel adaptive fuzzy sliding mode controller and application for vibration control of magnetorheological mount Proceedings of the 
Institution of Mechanical Engineers, Part C: Journal of Mechanical Engineering Science 228(13) 2285-2302

177.Guo D L, Hu H Y. 2002 Semi-active control of vehicle suspensions based on magnetorheological damper: modeling and directive adaptive control Journal of Vibration Engineering 15(1) 10-14

178.Guo D L, Hu H Y. 2002 Semi-active control of vehicle suspensions based on magnetorheological damper part II: indirect adaptive control and experiments Journal of Vibration Engineering 15(3) 285-289

179. Haibo L, Jianwei Y. 2009 Study on semi-active suspension system simulation based on magnetorheological damper Second International Conference on Intelligent Computation Technology and Automation IEEE 2 936-939

180. Yang J W, Sun S G, Liu H B. 2011 Adaptive relative control method for automotive semi-active suspension with magnetorheological damper Journal of System Simulation 23(9) 1951-1955

181.Laflamme S, Connor J J. 2009 Application of self-tuning Gaussian networks for control of civil structures equipped with magnetorheological dampers SPIE Smart Structures and Materials+ Nondestructive Evaluation and Health Monitoring. International Society for Optics and Photonics 72880M-72880M-12

182.Laflamme S, Yu T Y, Connor JJ. 2009 Intelligent controller for smart base isolation of masonry structures Cansmart 2009 International Workshop Smart Material and Structures 37-46

183.Laflamme S, Slotine J J E, Connor J J. 2011 Wavelet network for semi-active control Journal of Engineering Mechanics 137(7) 462-474

184.Tong S, Wang T, Tang J T. 2000 Fuzzy adaptive output tracking control of nonlinear systems Fuzzy Sets and Systems 111(2) 169-182

185.Chen B S, Lee C H, Chang Y C. 1996 Ho tracking design of uncertain nonlinear SISO systems: adaptive fuzzy approach IEEE Transactions on Fuzzy Systems 4(1) 32-43

186.Huang Y J, Kuo T C, Chang S H. 2008 Adaptive sliding-mode control for nonlinear systems with uncertain parameters IEEE Transactions on Systems, Man, and Cybernetics, Part B: Cybernetics 38(2) 534-539

187.Chan P T, Rad A B, Wang J. 2001 Indirect adaptive fuzzy sliding mode control: Part II: parameter projection and supervisory control Fuzzy Sets and Systems 122(1) 31-43

188. Holland J H. 1962 Outline for a logical theory of adaptive systems Journal of the ACM (JACM) 9(3): $297-314$

189.Bar-Kana I, Kaufman H. 1993 Simple adaptive control of large flexible space structures IEEE 
Transactions on Aerospace and Electronic Systems 29(4) 1137-1149

190.Goncalves F D and Ahmadian M 2003 A hybrid control policy for semi-active vehicle suspensions Shock and Vibration 10 59-69

191.Guo D L, Hu H Y and Yi J Q 2004 Neural network control for a semi-active vehicle suspension with a magnetorheological damper $J$ of Vibration and Control 10 461-71

192.Yu M, Liao C R, Chen W M and Huang S L 2006 Study on MR semi-active suspension system and its road testing Journal of Intelligent Material Systems and Structures 17 801-6

193.Du H P, Sze Kam Yim and Lam James 2005 Semi-active Ho control of vehicle suspension with magneto-rheological dampers Journal of Sound and Vibration. 283 981-96

194.Lam A H-F and Liao W-H 2003 Semi-active control of automotive suspension systems with magneto-rheological dampers International Journal of Vehicle Design. 33 50-75

195.Liu H and Nonami T H 2005 Semi-active fuzzy sliding mode control of full vehicle and suspensions Journal of Vibration and Control 11 1025-42

196.Stanway R, Sproston J L and Stevens N G 1987 Non-linear modeling of an electro-rheological vibration damper Journal of Electrostatics 20 167-84

197.Wereley, N.M., Pang, L., Kamath, G., 1998. Idealized hysteresis modeling of electrorheological and magnetorheological dampers Journal of Intelligent Material Systems and Structures 9(8) 642649

198.Wang L X and Kamath H 2006 Modeling hysteretic behavior in magnetorheological fluids and dampers using phase-transition theory Smart Materials and Structures 15 1725-33

199.Spencer B F Jr, Dyke S J, Sain M K and Carlson J D 1997 Phenomenological model for magnetorheological dampers Journal of Engineering Mechanics. ASCE 123 230-8

200. Yang G, Spencer B F Jr, Carlson J D and Sain M K 2002 Large-scale MR fluid dampers: modeling and dynamic performance considerations Engineering Structures 24 309-23

201.Guo D and Hu H 2005 Nonlinear stiffness of a magneto-rheological damper Nonlinear Dynamics $40241-9$

202.Kwok N M, Ha Q P, Nguyen T H, Li J and Samali B 2006 A novel hysteretic model for magnetorheological fluid dampers and parameter identification using particle swarm optimization Sensors Actuators A 132 441-51

203.Guo S, Yang S and Pan C 2006 Dynamical modeling of magneto-rheological damper behaviors Journal of Intelligent Material Systems and Structures 17 3-14 
204. $\mathrm{C}_{3}$ es s, meci $\mathrm{S}_{s}$ and Engin T 2010 Modeling and testing of a field-controllable magnetorheological fluid damper International Journal of Mechanical Sciences 52 1036-46.

205.Choi, S.B., Lee, S.K., Park, Y.P., 2001. A hysteresis model for the field dependent damping force of a magnetorheological damper Journal of Sound and Vibration 245 (2) 375-383

206.Hong K S, Sohn H C and Hedrick J K 2002 Modified skyhook control of semi-active suspensions: a new model, gains cheduling, and hardware-in-the-loop tuning Journal of Dynamic Systems, Measurement and Control, ASME 124 158-67.

207.Du H, Szeb K Y and Lam J 2005 Semi active H control of vehicle suspension with magnetorheological dampers Journal of Sound and Vibration 283 981-96

208. Shivaram A C and Gangadharan K V 2007 Statistical modeling of a magneto-rheological fluid damper using the design of experiments approach Smart Materials and Structures 16 1310-4.

209.Jin, G., Sain, M.K., Pham, K.D., Spencer, Jr., B.F., Ramallo, J.C.2001 Modeling MR-dampers: a nonlinear blackbox approach Proceedingsof the American Control Conference 429-434.

210.Savaresi S M, Bittanti S and Montiglio M 2005 Identificationof semi-physical and black-box nonlinear models: the caseof MR-dampers for vehicles control Automatica 41 113-27.

211.Leva, A., Piroddi, L., 2002. NARX-based technique for the modelling ofmagneto-rheological damping devices Smart Materials and Structures 11(1) 79-88

212. Atray V S and Roschke P N 2003 Design, fabrication, testingand fuzzy modeling of a large magneto-rheological damperfor vibration control in a railcar Proc. IEEE/ASME Joint Rail Conf. $223-9$

213. Ahn K K, Islam M A and Truong D Q 2008 Hysteresis modeling of magneto-rheological (MR) fluid damper by self-tuning fuzzy control Proc. ICCAS 2628-33

214. Chang, C.C., Roschke, P., 1998. Neural network modeling of a magnetorheological damper Journal of Intelligent Material Systems and Structures 9(9) 755-764

215.Chang, C.C., Zhou, L., 2002. Neural network emulation of inverse dynamics for a magnetorheological damper Journal of Structural Engineering 128(2) 231-239

216. J C Tud'on-Mart'inez, J JLozoya-Santos, R Morales-Menendez and R A Ramirez-Mendoza 2012 An experimental artificial-neural-network-based modeling of magneto-rheological fluid dampers Smart Materials and Structures 21085007

217. Haiping Du, James Lam, Nong Zhang 2006 Modelling of a magneto-rheological damper by evolving radial basisfunction networks Engineering Applications of Artificial Intelligence 19(8) 869-881 
218. Zhao-Dong Xu, Ya-Peng Shen and Ying-Qing Guo 2003 Semi-active control of structures incorporated with magnetorheological dampers using neural networks Smart Materials and Structures 12 80-87

219. Hao Wang, Xiaomei Shi 2010 Semi-Active Suspension Control Using the RNN Inverse System of MR Dampers $2^{\text {nd }}$ International Workshop on Intelligent Systems and Applications (ISA) 78-83

220. M. Zapateiro,N.Luo, H.R.Karimi,J.Veh1 2009 Vibration control of a class of semiactive suspension system using neural networkand backstepping techniques Mechanical Systems and Signal Processing 23 1946-1953

221. Jie Fu, Huijuan Yao, Miao Yu, Youxiang Peng 2013 An experimental model identification of magneto-rheological damper with neural network and its application in seat suspension system Proceeding of the $32^{\text {nd }}$ Chinese control conference $8769-8774$

222. Khaldoon A. Bani-Hani and Mashal A. Sheban 2006 Semi-active neuro-control for base-isolation system using magnetorheological (MR) dampers Earthquake Engineering Structural Dynamics 35 1119-1144

223.J C Tud'on-Mart'1nez, J JLozoya-Santos, R Morales-Menendez and R A Ramirez-Mendoza 2012 An experimental artificial-neural-network-based modeling of magneto-rheological fluid dampers Smart Materials and Structures 21085007

224.Xiao Min Dong, Miao Yu, Zushu Li, Changrong Liao and Weimin Chen 2009 Neural network compensation of semi-active control for magneto-rheological suspension with time delay uncertainty Smart Materials and Structures 18015014

225.Miao Yu, Seung Bok Choi, Xiaomin Dong, Changrong Liao 2009 Fuzzy neural network control for vehicle stability utilizing magnetorheological suspension system Journal of Intelligent Material Systems and Structures 20(4) 457-466

226. Girosi, J., Poggio, T. 1990 Neural networks and the best approximation property Biololgical Cybernetics 63 169-176

227. Park, J., Sandberg, I.W. 1991 Universal approximation using radial-basis-function networks Neural Computation 3 246-257

228.Powell M. 1985 Radial basis functions for multivariable integration: a review IMA Conference on Algorithm and Approximations and Data 23-28

229. Broomhead D S, Lowe D 1988 Radial basis functions, multivariable functional interpolation and adaptive networks Royal Signals and Radar Establishment 8 43-49

230. Jackson I R H. 1989 An order of convergence for some radial basis functions IMA Journal of 
Numerical Analysis 9(4) 567-587

231. Gallant, S. I. 1993 Neural Network Learning and Expert Systems MIT Press, New York

232. Daniel S. Yeung, Ian Cloete, Daming Shi, Wing W.Y. Ng 2010 Sensitivity Analysis for Neural Networks Springer-Verlag Berlin Heidelberg

233. Narendra K. S., Mukhopadhyay S. 1992 Neural Networks in Control Systems Decision and Control, 1992., Proceedings of the $31^{\text {st }}$ IEEE Conference on 1 1-6

234. Y. Q. Ni, Y. Chen, J.M. Ko, D.Q. Cao 2002 Neuro-control of cable vibration using semi-active magnetorheological dampers Engineering Structures 24 295-307

235. Semi Jansen, L. and Dyke, S. 2000 Semiactive control strategies for MR dampers: comparative study Journal of Engineering Mechanics 126(8), 795-803

236. Xiaomin Dong, Miao Yu, Zhushu Li 2009 Neural network compensation of semi-active control for magneto-rheological suspension with time delay uncertainty Smart Materials and Structure 18(1) $1-6$

237. D. L. Guo, H. Y. Hu, J. Q. Yi 2004 Neural network control for a semi-active vehicle suspension with a magnetorheological damper Journal of Vibration and Control 10(3) 461-471

238. A. K-Karamodin and H. H-Kazemi 2008 Semi-active control of structures using neuro-predictive algorithm for MR dampers Structural Control Health Monitoring 17(3) 237-253

239. Kumpati S. Narendra and Kannan Parthasarathy 1990 Identification and control of dynamical systems using neural networks IEEE Transactions on Neural Networks 1(1) 14-27

240. Chen A J 2005 Study on the dynamic response of automotive magneto-rheological dampers Master's Dissertation Chongqing University China

241.Par'e C A 1998 Experimental evaluation of semiactive magneto-rheological suspensions for passenger vehicles Master's Dissertation Faculty of the Virginia Polytechnic Institute and State University

242.Rumelhart, D.E., Hinton, G.E. and Williams, R.J. 1986 Learning internal representations by error propagation. In McClelland, J.L. and Rumelhart, D.E. (Eds.) Parallel Distributed Processing Cambridge, MA: MIT Press 1 318-362

243.Zames G. 1981 Feedback and optimal sensitivity: Model reference transformations, multiplicative seminorms, and approximate inverses IEEE Transactions on Automatic Control 26(2) 301-320

244.Doyle J. C., Glover Keith, Khargonekar P. P., Francis B. A. 1989 State-space solutions to standard $\mathrm{H}_{2}$ and $\mathrm{H} \infty$ control problems IEEE Transactions on Automatic Control 34(8) 831-847 
245.Jung H. J., Spencer B. F., Ni Y. Q., Lee I. W. 2004 State-of-the-art of semiactive control systems using MR fluid dampers in civil engineering applications Structural Engineering and Mechanics 17(3-4) 493-526

246.Haiping Du, Nong Zhang 2009 Model-based fuzzy control for buildings installed with magnetorheological dampers Journal of Intelligent Material Systems and Structures 9 1091-1105

247.Zapateiro M., H. R. Karimi, N. Luo 2011 Semiactive vibration control of nonlinear structures through adaptive backstepping techniques with $\mathrm{H} \infty$ performance International Journal of Systems Science 42(5) 853-861

248.M. Luu, M.D. Martinez-Rodrigo, V. Zabel, C. Könke 2014 Semi-active magnetorheological dampers for reducing response of high-speed railway bridges Control Engineering Practice 32 $147-160$

249.Y. Shi, T. C. Becker, M. Kurata, M. Nakashima $2013 \mathrm{H} \infty$ control in the frequency domain for a semi-active floor isolation system Frontiers of Structural and Civil Engineering 7(3) 264-275

250.Lam, A. H. F., W. H. Liao 2003 Semi-active control of automotive suspension systems with magneto-rheological dampers International Journal of Vehicle Design 33(1) 50-75

251.Haiping Du, James Lam, K. C. Cheung, Weihua Li, Nong Zhang 2013 Direct voltage control of magnetorheological damper for vehicle suspensions Smart Materials and Structures 22(10) 105016

252.Du H., K. Yim Sze, J. Lam 2005 Semi-active Hळ control of vehicle suspension with magnetorheological dampers Journal of Sound and Vibration 283(3) 981-996

253.Fallah M., R. B. Bhat, W. F. Xie 2012 Optimized control of semiactive suspension systems using $\mathrm{H}$ robust control theory and current signal estimation IEEE/ASME Transactions on Mechatronics 17(4) $767-778$

254.Choi S. B., H. S. Lee, Y. P. Park 2002 Hळ Control performance of a full-vehicle suspension featuring magnetorheological dampers Vehicle System Dynamics 38(5) 341-360

255.Prabakar R., C. Sujatha, S. Narayanan 2009 Optimal semi-active preview control response of a half car vehicle model with magnetorheological damper Journal of Sound and Vibration 326(3) $400-420$

256.Lu-Hang Zong, Xing-Long Gong, Shou-Hu Xuan, Chao-Yang Guo 2013 Semi-active Hœ control of high-speed railway vehicle suspension with magnetorheological dampers Vehicle System Dynamics 51(5) 600-626 
257.Yu-Jeong Shin, Won-Hee You, Hyun-Moo Hur,Joon-Hyuk Park 2014 Hœ control of railway vehicle suspension with MR damper using scaled roller rig. Smart Materials and Structures 23(9) 095023

258.Li, W., Y. Zhou, T. Tian 2010 Viscoelastic properties of MR elastomers under harmonic loading Rheologica Acta 49(7) 733-740

259.Du H., W. Li, N. Zhang 2011 Semi-active variable stiffness vibration control of vehicle seat suspension using an MR elastomer isolator Smart Materials and Structures 20(10) 105003

260. Sakai C., T. Terasawa, A. Sano 2005 Integration of bilinear $\mathrm{H} \infty$ control and adaptive inverse control for semi-active vibration isolation of structures $44^{\text {th }}$ IEEE Conference on Decision and Control, 2005 and 2005 European Control Conference Spain

261.Zhang X., Zhang H., Ahmadian M., Guo, K. 2011 Study on squeeze mode magneto-rheological engine mount with robust H-infinite control SAE Technical Paper 2011-01-0757

262.Gharapurkar A. A., Jahromi A. F., Bhat R. B. , Wen-Fang Xie 2013 Semi-active control of aircraft landing gear system using $\mathrm{H}$-infinity control approach International Conference on Connected Vehicles and Expo Las Vegas, NV

263.Sammier D., O. Sename, L. Dugard 2003 Skyhook and $\mathrm{H} \infty$ control of semi-active suspensions: some practical aspects Vehicle System Dynamics 39(4) 279-308

264.L.C. Félix-Herrán, D. Mehdi, J. de J. Rodríguez-Ortiz, R. Soto, R. Ramírez-Mendoza 2012 Hœ control of a suspension with a magnetorheological damper International Journal of Control 85(8) $1026-1038$

265.Kim J. H., F. Jabbari 2002 Actuator saturation and control design for buildings under seismic excitation. Journal of Engineering Mechanics 128(4) 403-412

266.Zhou K., P. P. Khargonekar 1988 An algebraic Riccati equation approach to Hळo optimization Systems \& Control Letters 11(2) 85-91

267.G. Priyandoko, M. Mailah, and H. Jamaluddin 2009 Vehicle active suspension system using skyhook adaptive neuro active force control Mechanical Systems and Signal Processing 23 855868

268. H.-X. Li and S. Tong 2003 A hybrid adaptive fuzzy control for a class of nonlinear MIMO systems Fuzzy Systems, IEEE Transactions on 11 24-34

269. M. Yu, S.-B. Chol, X. Dong, and C. Liao 2008 Fuzzy neural network control for vehicle stability utilizing magnetorheological suspension system Journal of Intelligent Material Systems and Structures 20 457-466 
270. P. W. Nugroho, W. Li, H. Du, G. Alici, and J. Yang 2014 An adaptive neuro fuzzy hybrid control strategy for a semiactive suspension with magneto rheological damper Advances in Mechanical Engineering 2014

271. M. Ahmadian and C. A. Pare 2000 A quarter-car experimental analysis of alternative semiactive control methods," Journal of Intelligent Material Systems and Structures 11 604-612

272. X. Song, M. Ahmadian, and S. Southward 2003 An adaptive semiactive control algorithm for vehicle suspension systems ASME 2003 International Mechanical Engineering Congress and Exposition 219-228

273. N. Eslaminasab, M. Biglarbegian, W. W. Melek, and M. F. Golnaraghi 2007 A neural network based fuzzy control approach to improve ride comfort and road handling of heavy vehicles using semi-active dampers," International Journal of Heavy Vehicle Systems 14 135-157

274. G. Yan and L. L. Zhou 2006 Integrated fuzzy logic and genetic algorithms for multi-objective control of structures using MR dampers Journal of Sound and Vibration 296 368-382

275. S. S. Ge, C. C. Hang, and T. Zhang 1999 Adaptive neural network control of nonlinear systems by state and output feedback Systems, Man, and Cybernetics, Part B: Cybernetics, IEEE Transactions on 29 818-828

276. M. Zhihong, H. R. Wu, and M. Palaniswami 1998 An adaptive tracking controller using neural networks for a class of nonlinear systems Neural Networks, IEEE Transactions on 9 947-955

277. C.-M. Lin and C.-F. Hsu 2003 Neural-network hybrid control for antilock braking systems Neural Networks, IEEE Transactions on 14 351-359

278. K. Nam 1999 Stabilization of feedback linearizable systems using a radial basis function network Automatic Control, IEEE Transactions on 44 1026-1031

279. J. T. Spooner and K. M. Passino 1999 Decentralized adaptive control of nonlinear systems using radial basis neural networks Automatic Control, IEEE Transactions on 44 2050-2057

280. J.-Y. Choi and J. A. Farrell 2000 Nonlinear adaptive control using networks of piecewise linear approximators Neural Networks, IEEE Transactions on 11 390-401

281. M. Hojati and S. Gazor 2002 Hybrid adaptive fuzzy identification and control of nonlinear systems Fuzzy Systems, IEEE Transactions on 10 198-210

282. M. M. Rashid, N. A. Rahim, M. A. Hussain, and M. Rahman 2011 Analysis and experimental study of magnetorheological-based damper for semiactive suspension system using fuzzy hybrids, Industry Applications, IEEE Transactions on, 47 1051-1059

283. J.-J. E. Slotine and W. Li 1991 Applied nonlinear control 199: Prentice-Hall Englewood Cliffs, 
284. A. Lewis and A. Sinha 1999 Sliding mode control of mechanical systems with bounded disturbances via output feedback Journal of Guidance, Control, and Dynamics 22 235-240

285. Y. Chen 2009 Skyhook surface sliding mode control on semi-active vehicle suspension system for ride comfort enhancement Engineering 123

286. M. Ahmadian and N. Vahdati 2006 Transient dynamics of semiactive suspensions with hybrid control," Journal of Intelligent Material Systems and Structures 17 145-153

287. L. C. Félix-Herrán, J. de Jesús Rodríguez-Ortiz, R. Soto, and R. Ramírez-Mendoza 2008 Modeling and control for a semi-active suspension with a magnetorheological damper including the actuator dynamics Electronics, Robotics and Automotive Mechanics Conference, 2008. CERMA'08, 2008 338-343

288. S. Dyke, B. Spencer Jr, M. Sain, and J. Carlson 1996 Modeling and control of magnetorheological dampers for seismic response reduction Smart Materials and Structures 5565

289. X.-M. Dong, M. Yu, C.-R. Liao, and W.-M. Chen 2010 Comparative research on semi-active control strategies for magneto-rheological suspension Nonlinear Dynamics 59 433-453

290. B. Kosko 1987 Adaptive bidirectional associative memories Applied optics 26 4947-4960

291. J. H. Holland 1962 Outline for a logical theory of adaptive systems Journal of the ACM (JACM) 9 297-314

292. P. Nugroho, H. Du, W. Li, and G. Alici 2012 A new adaptive fuzzy-hybrid control strategy of semi-active suspension with magneto-rheological damper $Y$. Gu \& S. Saha (Eds.), 4th International Conference on Computational Methods 1-9 293

293.Juan de Vicente, Daniel J. Klingenbergb and Roque Hidalgo-Alvareza 2011 Magnetorheological fluids: a review Soft Matter 11(8) 3701-3710, DOI: 10.1039/C0SM01221A

294.Mickaël Kargulewicz, Ivan Iordanoff, Victor Marrero and John Tichy 2011 Modeling of magnetorheological fluids by the discrete element method, Journal of Tribology 134(3), 0317061 9 doi:10.1115/1.4006021

295. Ali Ghaffari, Seyed Hassan Hashemabadi and Mahshid Ashtiani 2015 A review on the simulation and modeling of magnetorheological fluids Journal of Intelligent Material Systems and Structures 26(8) 881-904, doi:10.1177/1045389X14546650

296.M. Ashtiani, S.H. Hashemabadi and A. Ghaffari 2015 A review on the magnetorheological fluid preparation and stabilization Journal of Magnetism and Magnetic Materials 374(1) 716-730, doi:10.1016/j.jmmm.2014.09.020

297.K. Han, Y. T. Feng and D. R. J. Owen 201 Three-dimensional modelling and simulation of 
magnetorheological fluids International Journal for Numerical Methods in Engineering 84(11) 1273-1302, DOI: $10.1002 /$ nme.2940

298. Yancheng $\mathrm{Li}$, Jianchun $\mathrm{Li}$, Weihua $\mathrm{Li}$ and Haiping $\mathrm{Du} 2014$ A state-of-the-art review on magnetorheological elastomer devices, Smart Materials and Structures 23(12) 123001, doi:10.1088/0964-1726/23/12/123001

299.D H Wang and W H Liao 2011 Magnetorheological fluid dampers: a review of parametric modelling Smart Materials and Structures 20(2) 023001, doi:10.1088/0964-1726/20/2/023001

300.Xiaocong Zhu, Xingjian Jing and Li Cheng 2012 Magnetorheological fluid dampers: A review on structure design and analysis Journal of Intelligent Material Systems and Structures 23(8) 839-873, doi: $10.1177 / 1045389$ X12436735

301.Abdul Yasser Abd Fatah 2015 A review of design and modeling of magnetorheological valve International Journal of Modern Physics B 29(4) 1530004, DOI: 10.1142/S0217979215300042

302.Xu Biao, Luo Yiping and Ren Hongjuan 2014 Review on magneto-rheological fluid and its application American Journal of Nanoscience and Nanotechnology 2(4) 70-74, doi : 10.11648/j.nano.20140204.12 


\section{Legends for the Tables and Illustrations}

Table 1. Commercially available vehicles equipped with MRF damper

Table 2. Controllers for MRF and MRE Application Systems

Figure 1. A concept of a skyhook controller

Figure 2. A block diagram of PID controller

Figure 3. A block diagram of optimal control system (a) LQG (b) LQR

Figure 4. A concept block diagram of a sliding mode controller

Figure 5. A block diagram of a fuzzy control system

Figure 6. A block diagram of a model reference adaptive control system

Figure 7 . Block diagram of the gradient update system

Figure 8. Block diagram of the self-tuning regulators

Figure 9. A block diagram of a neural network control system

Figure 10. A block diagram of H-infinity control system

Figure 11. A block diagram of a hybrid fuzzy neural network control system 
Table 1. Commercially available vehicles equipped with MRF damper

\begin{tabular}{|c|l|l|}
\hline No & \multicolumn{1}{|c|}{ Year } & \multicolumn{1}{|c|}{ Vehicle Type } \\
\hline 1 & 2002 & Cadillac Seville \\
\hline 2 & 2002 & Chevrolet Corvette \\
\hline 3 & 2003 & Cadillac SRX \\
\hline 4 & 2003 & Cadillac XLR \\
\hline 5 & 2004 & Cadillac STS \\
\hline 6 & 2005 & Cadillac DTS \\
\hline 7 & 2005 & Buick Lucerne \\
\hline 8 & 2006 & Ferrari 599 GTB \\
\hline 9 & 2006 & Acura MDX \\
\hline 10 & 2007 & Audi TT \\
\hline 11 & 2007 & Audi R8 \\
\hline 12 & 2008 & Cadillac Escalade \\
\hline 13 & 2008 & Holden HSV W427 \\
\hline 14 & 2009 & Ferrari California \\
\hline 15 & 2009 & Cadillac CTS-V \\
\hline 16 & 2010 & Audi A3/S3 \\
\hline 17 & 2010 & Acura ZDX \\
\hline 18 & 2011 & Audi R8 Spyder \\
\hline 19 & 2011 & Ferrari 458 Italia \\
\hline 20 & $2013-$ & Cadillac CTS \\
& 2014 & \\
\hline 21 & $2013-$ & Chevrolet Corvette \\
& 2014 & \\
\hline 22 & $2013-$ & Ferrari LaFerrari \\
\hline 23 & 2014 & \\
\hline 24 & $2013-$ & Ferrari FF \\
\hline 25 & $2014-$ & Ferrari F12 Berlinetta \\
& 2014 & \\
\hline & & Audi A3/S3 \\
\hline
\end{tabular}


Table 2. Controllers for MRF and MRE Application Systems

\begin{tabular}{|c|c|c|}
\hline $\begin{array}{l}\text { Controller } \\
\text { Types }\end{array}$ & $\begin{array}{c}\text { Application } \\
\text { Devices/Systems }\end{array}$ & Related References \\
\hline \multirow{4}{*}{ Skyhook } & MR seat damper & {$[1],[2],[3],[11]$} \\
\hline & MR suspensions & {$[5],[6],[9],[10],[12],[14],[15],[17],[186],[239],[255]$} \\
\hline & MR landing gear & [8] \\
\hline & MR mount & {$[16]$} \\
\hline \multirow{4}{*}{ PID } & $\begin{array}{l}\text { Passenger } \\
\text { vehicles }\end{array}$ & [19] \\
\hline & MR suspensions & {$[20]$} \\
\hline & MR brake & {$[22],[23]$} \\
\hline & $\begin{array}{l}\text { Haptic master } \\
\text { system }\end{array}$ & [24] \\
\hline \multirow{6}{*}{ LQR/LQG } & Truss structures & {$[29]$} \\
\hline & $\begin{array}{l}\text { Space flexible } \\
\text { structure }\end{array}$ & {$[30]$} \\
\hline & Cable system & {$[31],[36]$} \\
\hline & MR mount & {$[32],[37]$} \\
\hline & MR suspension & {$[33],[41],[44],[45],[46],[47]$} \\
\hline & Building & {$[39],[43]-1-$} \\
\hline \multirow{5}{*}{$\begin{array}{l}\text { Sliding } \\
\text { Mode } \\
\text { Control }\end{array}$} & MR suspension & {$[49],[50],[52],[54],[55],[62]$} \\
\hline & MR brake & {$[51],[56]$} \\
\hline & MR mount & [59] \\
\hline & $\begin{array}{l}\text { Haptic master } \\
\text { system }\end{array}$ & {$[60]$} \\
\hline & Bed stage & [61] \\
\hline \multirow{6}{*}{$\begin{array}{l}\text { Fuzzy } \\
\text { Control }\end{array}$} & MR suspension & {$[63],[64],[65],[68],[69],[70],[71],[72],[73],[89],[90],[91],[93]$} \\
\hline & $\begin{array}{l}\text { Biomedical } \\
\text { system }\end{array}$ & [66] \\
\hline & Bridge structures & {$[78],[80]$} \\
\hline & Railcar & [92] \\
\hline & Ship lift & [94] \\
\hline & Building & {$[98],[99],[101]$} \\
\hline \multirow{11}{*}{$\begin{array}{l}\text { Adaptive } \\
\text { Control }\end{array}$} & MR Suspensions & $\begin{array}{l}{[107],[110],[111],[117],[131],[135],[136],[140],[150],,[151],[152],[15} \\
3],[158],[159],[161],[162],[163],[164]\end{array}$ \\
\hline & Building & {$[122],[123],[137],[138],[141],[142],[165]$} \\
\hline & MR brake & {$[124],[156]$} \\
\hline & $\begin{array}{l}\text { Assistive knee } \\
\text { braces }\end{array}$ & {$[126],[127],[129]$} \\
\hline & Leg exoskeleton & {$[128]$} \\
\hline & $\begin{array}{l}\text { Gun recoil } \\
\text { damper }\end{array}$ & {$[145]$} \\
\hline & Engine & {$[147]$} \\
\hline & Locomotive & [148] \\
\hline & MR mount & {$[160]$} \\
\hline & $\begin{array}{l}\text { Masonry } \\
\text { structures }\end{array}$ & [166] \\
\hline & $\begin{array}{l}\text { Space flexible } \\
\text { structure }\end{array}$ & [173] \\
\hline \multirow{3}{*}{$\begin{array}{c}\text { Neural } \\
\text { Network } \\
\text { Control }\end{array}$} & MR suspensions & $\begin{array}{l}{[174],[175],[176],[186],[189],[197],[198],[199],[202],[212],[215],[21} \\
6]\end{array}$ \\
\hline & Railcar & {$[191]$} \\
\hline & Cable system & [211] \\
\hline \multirow{2}{*}{$\begin{array}{l}\text { H-infinity } \\
\text { Control }\end{array}$} & Civil structures & {$[220],[224],[237]$} \\
\hline & Railway bridge & [223] \\
\hline
\end{tabular}




\begin{tabular}{|c|l|l|}
\hline & MR suspensions & {$[225],[227],[228],[229],[235],[236][231]$} \\
\hline & MR mount & {$[233]$} \\
\cline { 2 - 4 } & $\begin{array}{l}\text { Aircraft landing } \\
\text { gear }\end{array}$ & {$[234]$} \\
\hline $\begin{array}{l}\text { Hybrid } \\
\text { Control }\end{array}$ & MR suspensions & {$[239],[241],[242],[243],[244],[255],[256],[257],[260]$} \\
\cline { 2 - 3 } & Braking system & {$[248]$}
\end{tabular}




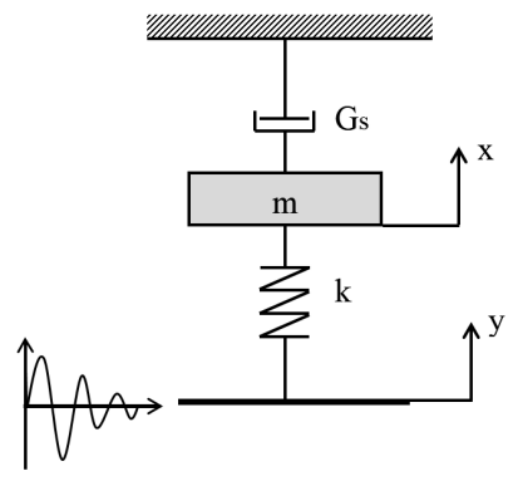

Figure 1. A concept of a skyhook controller 


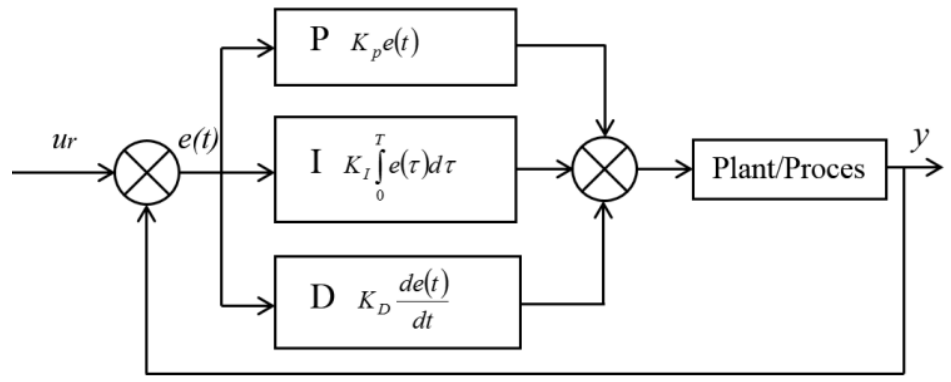

Figure 2. A block diagram of PID controller 


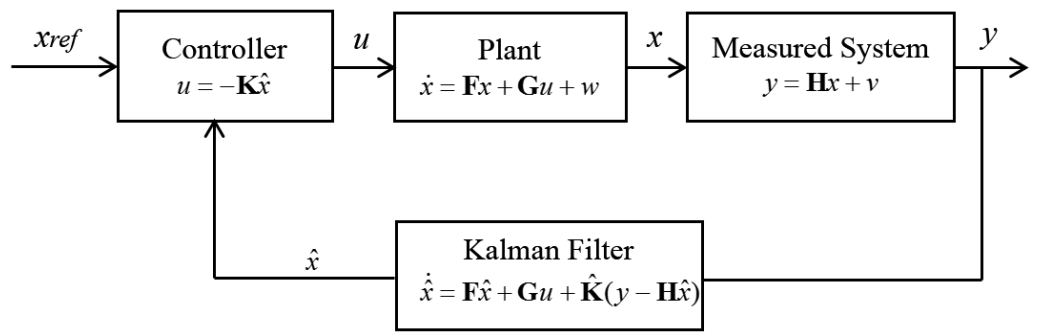

(a)

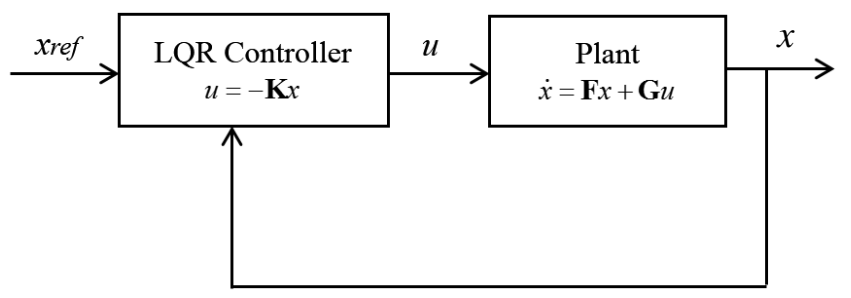

(b)

Figure 3. A block diagram of optimal control system (a) LQG (b) LQR 


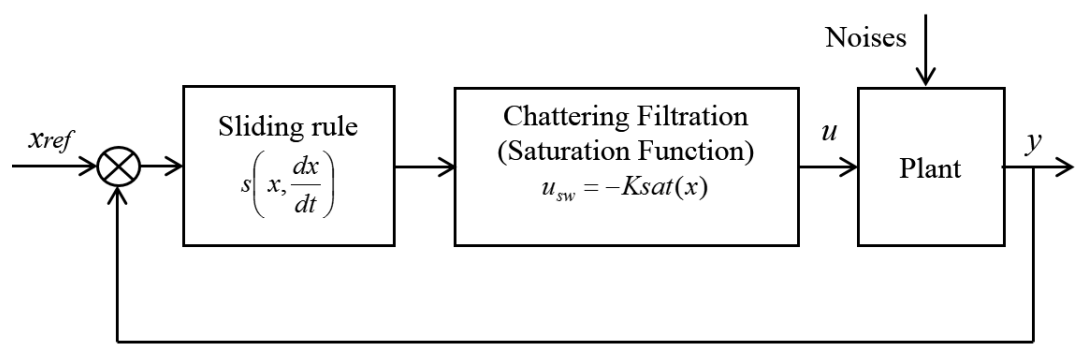

Figure 4. A concept block diagram of a sliding mode controller 


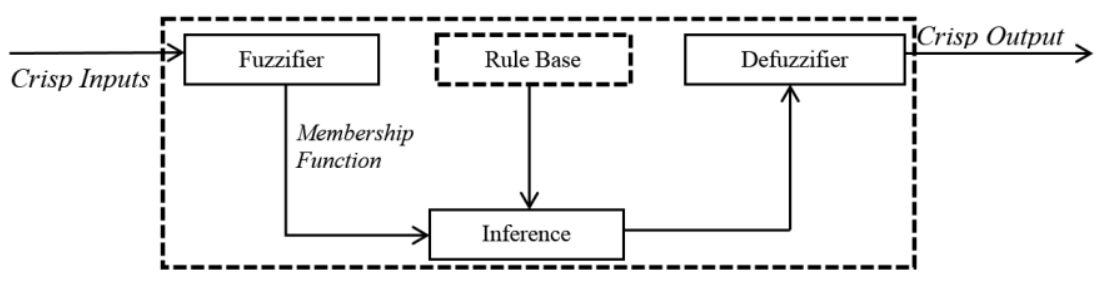

Figure 5. A block diagram of a fuzzy control system 


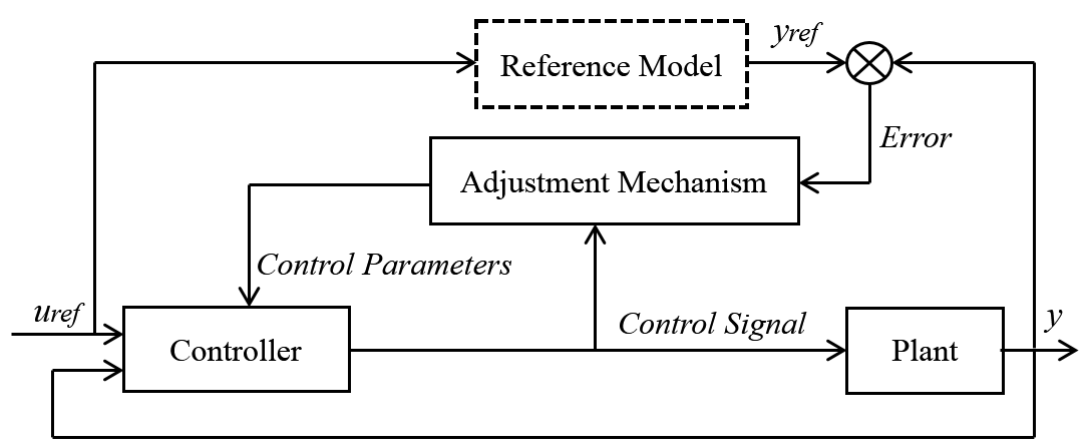

Figure 6. A block diagram of a model reference adaptive control system 


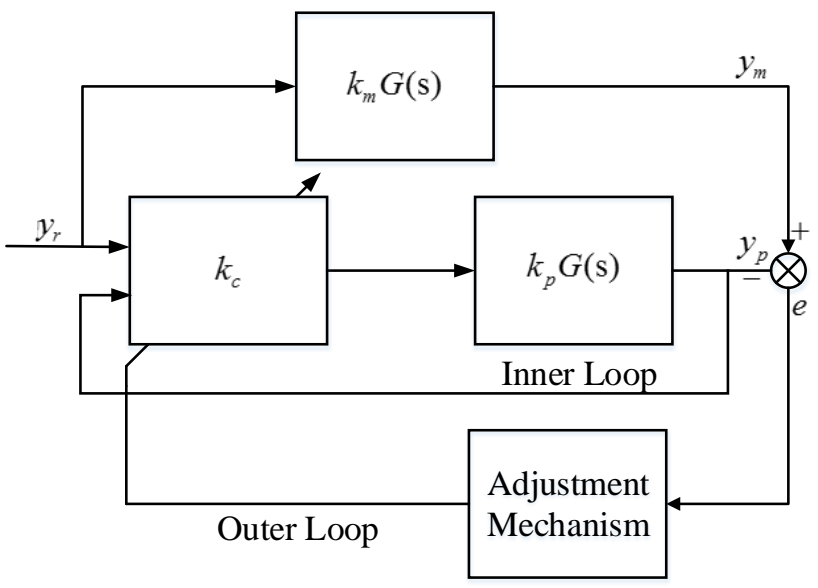

Figure 7. Block diagram of the gradient update system 


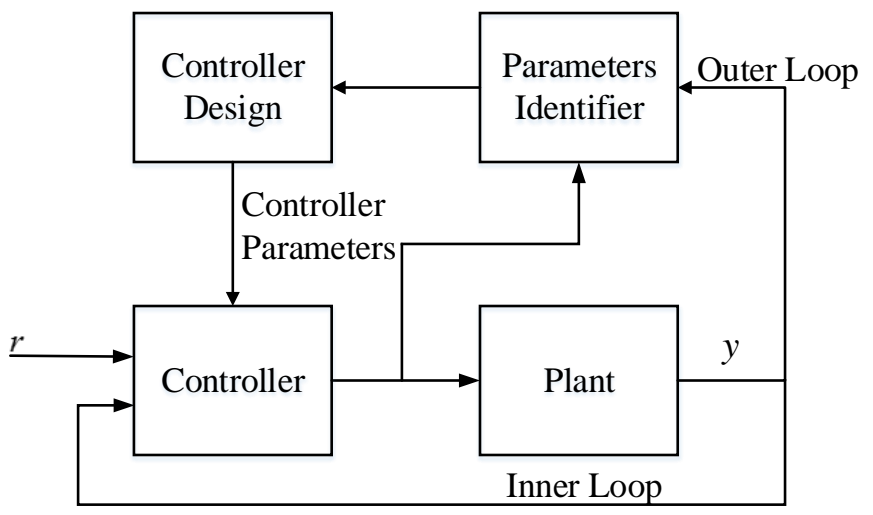

Figure 8. Block diagram of the self-tuning regulators 


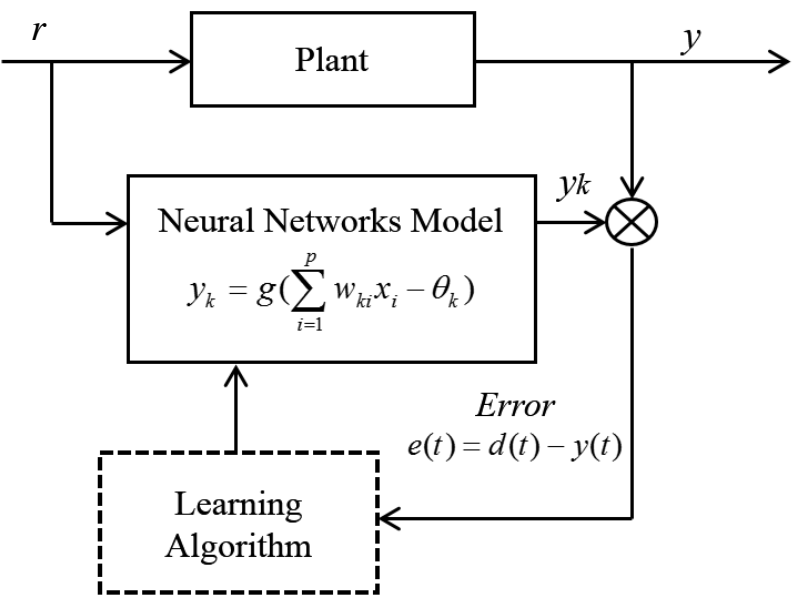

Figure 9. A block diagram of a neural network control system 


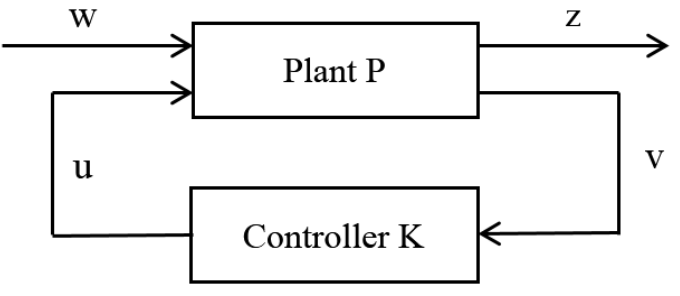

Figure 10. A block diagram of $\mathrm{H}$-infinity control system 


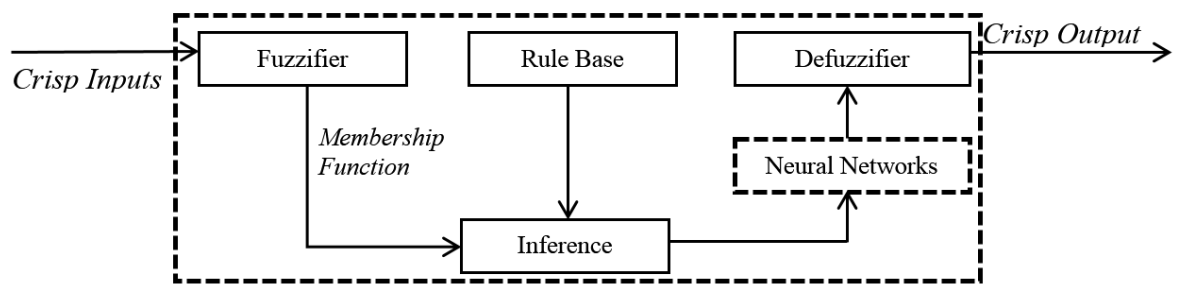

Figure 11. A block diagram of a hybrid fuzzy neural network control system 